\title{
NBSIR 85-3196
}

\section{Slide-Rule Estimates of Fire Growth}

1

J. R. Lawson

J. G. Quintiere

U.S. DEPARTMENT OF COMMERCE

National Bureau of Standards

National Engineering Laboratory

Center for Fire Research

Gaithersburg, MD 20899

June 1985

Supported in part by: 



\section{SLIDE-RULE ESTIMATES OF FIRE GROWTH}

J. R. Lawson

J. G. Quintiere

U.S. DEPARTMENT OF COMMERCE

National Bureau of Standards

National Engineering Laboratory

Center for Fire Research

Gaithersburg, MD 20899

June 1985

Supported in part by:

U.S. David Taylor Naval Ship

Research and Development Center

Washington, DC

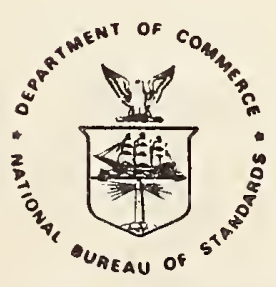

U.S. DEPARTMENT OF COMMERCE, Malcolm Baldrige, Secretary NATIONAL BUREAU OF STANDARDS, Ernest Ambler, Director 



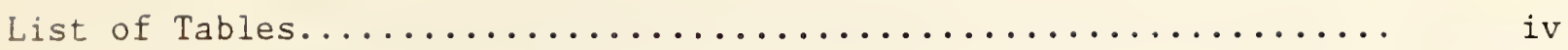

List of Figures............................... v v

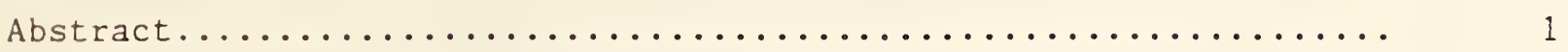

1. Introduction............................. 1

2. Fire Size and Growth Rates...................... 1

3. Radiant Heat Flux to a Target..................... 8

4. Flame Height............................... 9

5. Radial Flame Impingement and Heat Flux to a Ceiling........ 10

6. Smoke................................... 12

7. Time to Carbon Monoxide Hazard With Smoldering Fires........ 14

8. Temperature Rise of Hot Gases in a Compartment........... 16

9. Ventilation Flow Rate............................. 17

10. Does Flashover Occur?............................ 19

11. Mass Burning Rate in Ventilation Limited Fires............ 19

12. Corridor Smoke Transfer and Filling................. 21

13. Smoke Concentration and Visibility................... 24

14. Estimation of Flame Spread Rates.................... 28

15. Flame Spread Over Liquids....................... 30

16. Fully Developed Fire Burn Time................... 31

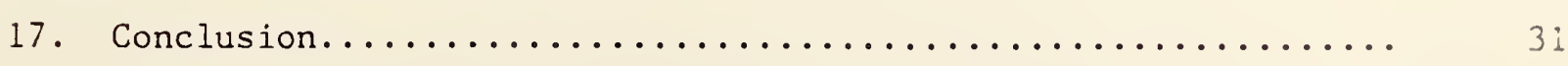

18. References............................... 32

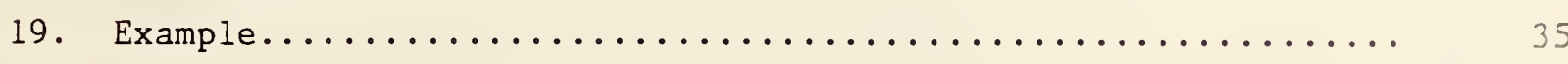


List of Tables

$\underline{\text { Page }}$

Table B1. Results for PMMA pool fires of varying

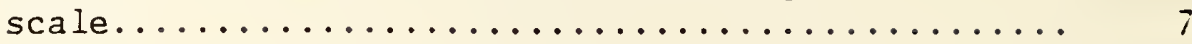

Table B2. Burning rates for liquid pool fires............ 8

Table B3. Smoke properties for selected materials

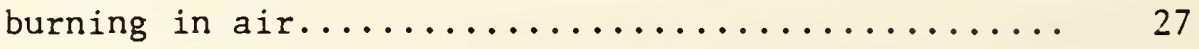

Table E1. Fire growth predictions................. 42

Table E2. Room smoke filling time predictions, steady

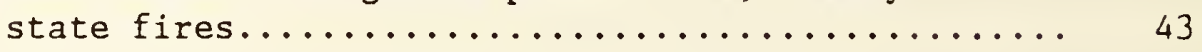

Table E3. Summary of critical event predictions.......... 43 
Figure Bl. Sketch of a wood crib.................. 2

Figure B2. Reduced specific burning rate as a function of the crib porosity for ponderosa pine

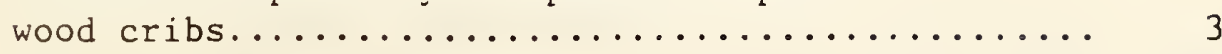

Figure B3. Rate of mass loss plot for easy chair......... 5

Figure B4. Rate of mass loss plot for sofa with

"California foam" cushions................. 5

Figure B5. Weight loss for cotton and mixed fiber core

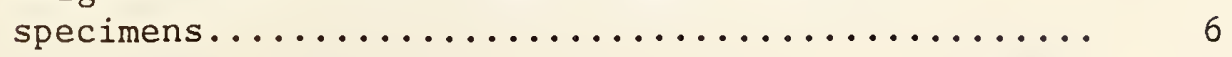

Figure B6. Fire radiant heat transfer to a target......... 8

Figure B7. Flame height dependence on heat release parameters........................... 9

Figure B8a. For open flames..................... 10

Figure B8b. Corner fire scenario.................... 10

Figure B9. Flame length and geometric environment......... 11

Figure B10. Room smoke filling model................ 13

Figure B11. Ceiling layer height versus time and heat

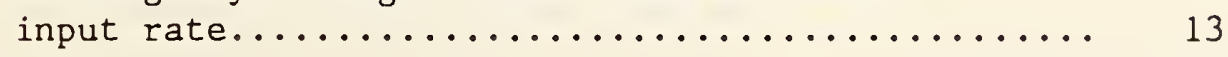

Figure B12. Compartment temperature rise example.......... 16

Figure B13. Sketch of compartment ventilation problem....... 18

Figure B14. Corridor smoke transport................ 21

Figure B15. Smoke filling by a fire room to a closed

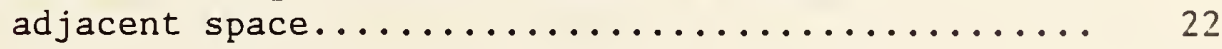

Figure B16. Dimensionless corridor smoke filling time....... 23

Figure B17. Visibility results derived from Rasbash [27],

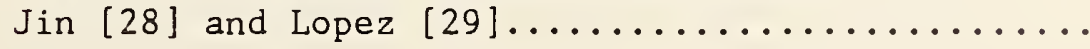

Figure B18. Smoke production for plywood as a function of ventilation factor from Saito............. 27

Figure B19. Sketch of flame spread model.............. 28

Figure B20. Schematic of the flame spreading rate as a function of the liquid temperature of the fuel.... 30 
Figure E1. Room fire example................... 35

Figure E2. Mass loss rate for fire growth example......... 44

Figure E3. Heat flux predictions in room for fire growth example........................... 45

Figure E4. Flame height and extension across ceiling for fire growth example................. 46

Figure E5. Room temperature rise for fire growth example..... 47

Figure E6. Mass flow rate into the room for fire growth example......................... 48

Figure E7. Visibility in corridor for fire growth

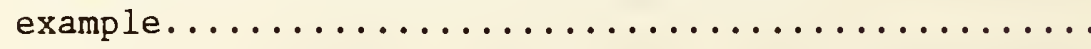




\section{SLIDE-RULE ESTIMATES OF FIRE GROWTH}

by

J.R. Lawson and J.G. Quintiere

Abstract

A series of prediction methods have been assembled to provide an analytical basis for estimating fire growth in compartmens. Solutions for each prediction method can be made using programmable scientific calculators. Prediction methods are presented for: fire size and growth rates, mass loss rates, radiant heat flux, flame height, radial flame impingement, heat flux to a ceiling, smoke filling of a room, carbon monoxide hazard with smoldering fires, temperature rise in a compartment, ventilation flow rate, flashover ocurrence, corridor smoke transfer and filling, smoke concentration, visibility, flame spread rates, and fire burn time.

These predictive methods are useful for estimating many of the critical elements related to fire behavior and help provide a better understanding of this complex phenomenon.

This report appears as Appendix B in Fire Growth in Combat Ships by J.G. Quintiere, H.R. Baum and J.R. Lawson, NBSIR 85-3159.

Key words: Calculators; computer programs; fire growth; fire models; room fires.

\section{Int roduction}

The purpose of this paper is to provide an analytical basis for estimating the growth of fire in compartments and its consequences. All prediction methods have been selected to allow for solutions to be made using programmable scientific calculators or pocket computers. The paper consists of a series of equations or data each of which describes a particular process in a fire's growth. Only minor discussions of theory are presented to provide some understanding of concepts related to the problem in question. For more information on each process discussed, refer to the appropriate reference materials. The equations presented will apply only to specific fuels or conditions and hence will be approximate when used for more complex or different situations. Also, any consideration of these equations as constituting a dynamic interacting fire system will be filled with inconsistencies. Nevertheless, this series of equations can provide a reasonable sense of the quantitative features of fire growth. It will relate to material type - solids or liquids - not specific materials. For specific materials other than those addressed in the text, one would have to acquire data that is unique to the materials being studied. Moreover, the state-of-the-art does not fully allow for fire predictions of specific materials.

\section{Fire Size and Growth Rates}

In order to make fire growth predictions, one must make a basic assumption about what material is burning. This assumption is used to calculate an estimated burning rate for the model and is a key factor for calculating other 
fire characteristics associated with fire growth. The four basic types of fuels identified with fire are usually classed as:
A. Solids (non-metals)
B. Liquids
C. Electrical Equipment
D. Metals

In this paper we shall consider only some representative ways of estimating Class A and Class B materials. For Class A we will consider first a wood crib as representative of a complex structure; then a solid surface like a mattress, chair or slab of material. For Class B materials, a method for estimating burning rates is suggested and input data will be provided for some common liquid fuels.

In 1976, Delichatosios reported work accomplished on the study of fire growth in wood cribs [1]. In his work, it was shown that a simple model could be used to predict fire growth rates for wood cribs. This model is put to use in this report for the same purpose. The model pays particular attention to crib geometry, surface area exposed for burning, and the wood's thermal properties. The equation used for estimating burning rate, $\dot{\mathrm{m}}_{f}$, for cribs ignited in the center is,

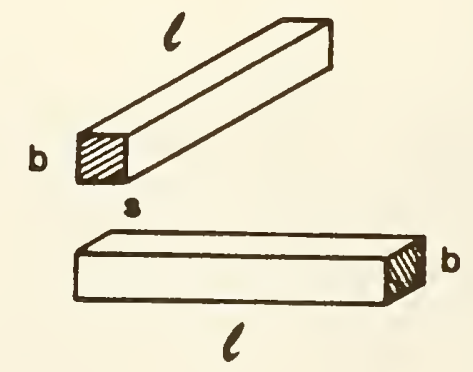

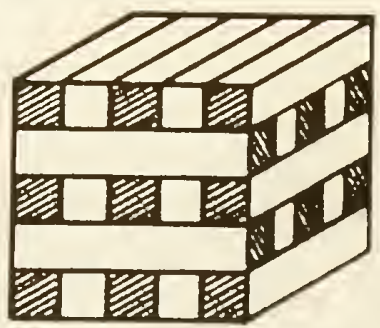

Square cribs

Figure B1. Sketch of a Wood Crib.

$$
\dot{\mathrm{m}}_{\mathrm{f}}=\dot{\mathrm{m}}^{\prime \prime} A_{\mathrm{s}} \frac{\pi}{2}{\frac{\mathrm{t}}{\mathrm{t}_{\mathrm{o}}}}^{2} \text { for } t \leq t_{0}
$$

$\dot{\mathrm{m}}^{\prime}$ - $\quad$ specific burning rate found by: $\dot{\mathrm{m}}^{\prime}=\mathrm{cb}^{-1 / 2} \mathrm{f}(\mathrm{P})$ where

$$
\begin{aligned}
& c \sim 10^{-3} \mathrm{~g} / \mathrm{cm}^{3 / 2} \cdot \mathrm{s} \\
& \mathrm{b}-\text { wood stick thickness }(\mathrm{cm}) \\
& \mathrm{f}(\mathrm{P})-\text { found in Figure } \mathrm{B} 2 \\
& \mathrm{P}=\mathrm{A}_{\mathrm{v}} \mathrm{s}^{1 / 2} \mathrm{~b}^{1 / 2} \mathrm{~A}_{\mathrm{s}}
\end{aligned}
$$


$A_{S}-\quad$ total exposed surface area of wood in the crib $=4 \ell b n N$ where

$$
\begin{aligned}
& 2 \text { - stick length }(\mathrm{cm}) \\
& \mathrm{s} \text { - stick spacing }(\mathrm{cm})=\ell-\mathrm{nb} \\
& \mathrm{n} \text { - sticks per crib layer } \\
& \mathrm{N} \text { - layers of sticks in crib }
\end{aligned}
$$

$A_{V}-\quad$ total shaft cross-sectional area $=s^{2} \cdot\left(\right.$ number $\left.=(n-1)^{2}\right)$ of shafts)

$t$ - time in seconds

$t_{0}-\quad$ time for flames to spread to the outer edge of $c r i b=n /(\sqrt{2} \xi)$

$$
\xi \sim 0.045 \mathrm{~s}^{-1}
$$

$$
\dot{\mathrm{m}}_{\mathrm{E}}=\mathrm{A}_{\mathrm{S}} \mathrm{cb}-1 / 2 \mathrm{f}(\mathrm{P}) \text { for } t>t_{\mathrm{o}}
$$

where $f(P)$ is plotted in Figure $B 2$ and when $P>0.07, f(P)=1$.

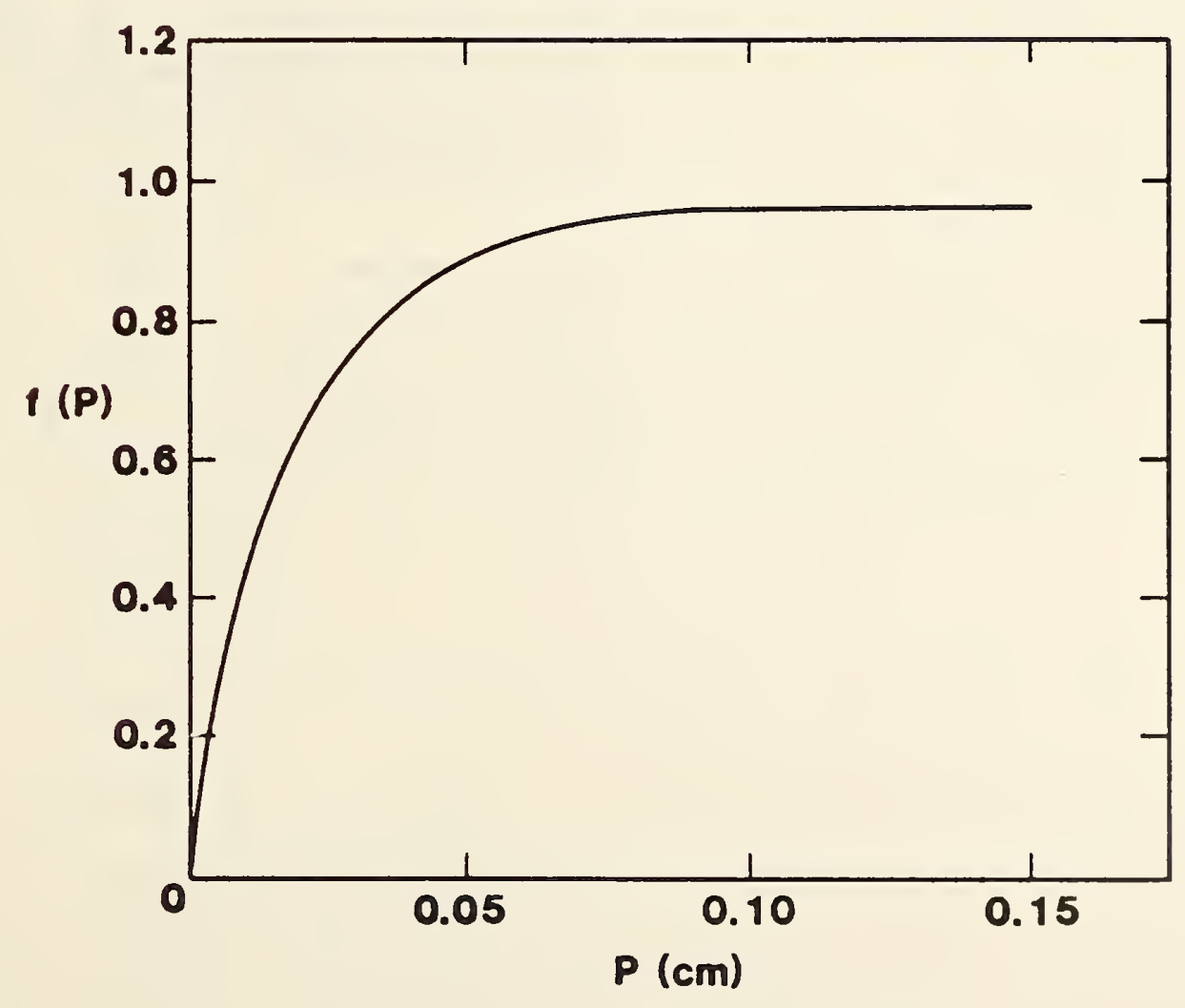

Figure B2. Reduced specific burning rate as a function of the crib porosity for ponderosa pine wood cribs (taken from Heskestad) [2]. 
BURNING RATES FOR FURNISHINGS. With more complex solids like fumishings, representative data is drawn from a report by Lawson, et al. [3]. Figure B3 exhibits the mass loss rate for a typical stuffed chair and Figure B4 provides data on a typical three seat sofa. Mass loss rate data for burning mattresses is obtained from a report published in 1977 by Babrauskas [4]. Figure B5 presents data for cotton and mixed fiber core mattress specimens. Data from these and other reports can be substituted in for calculations on burning rates for furnishings. Furnishings are complex solids that do not currently lend themselves to simple fire modeling, other common solid materials do.

BURNING RATES FOR PLASTIC POOL FIRES. The burning rate for polyurethane foam was estimated with the following pool fire model developed by orloff [5].

$$
\begin{aligned}
& \dot{\mathrm{m}}_{\mathrm{f}}=\alpha \mathrm{e}^{(\alpha t-\beta)} \mathrm{g} / \mathrm{s} \\
& \text { where } \alpha=0.033 \mathrm{~s}^{-1}
\end{aligned}
$$

$B=1.29$ (corresponds to a time shift of 30.35 which accounts for a particular ignition character in this experiment)

$t=t i m e$ in seconds

for the period $80<t<170$ s. 


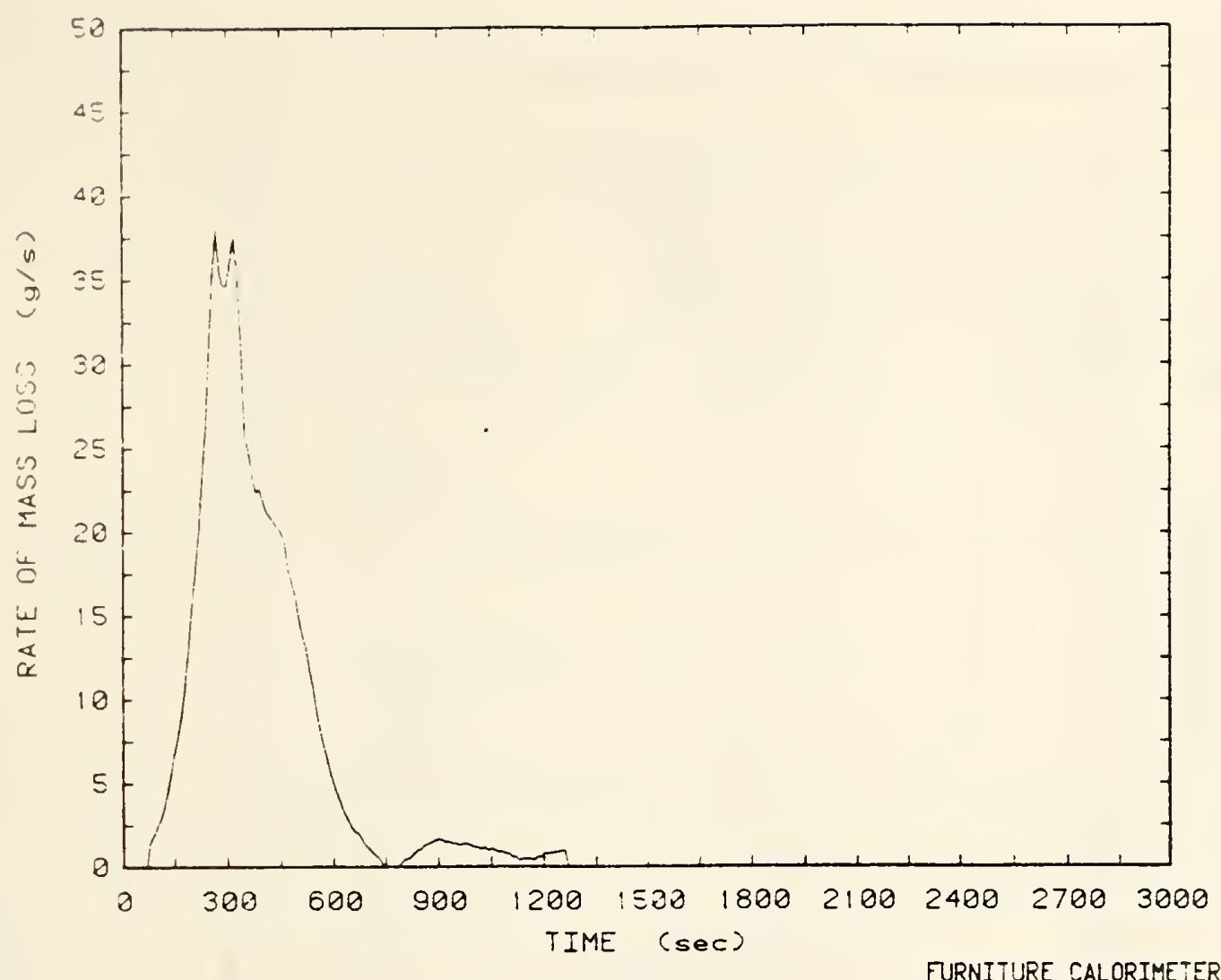

Figure B3. Rate of mass loss plot for easy chair [3].

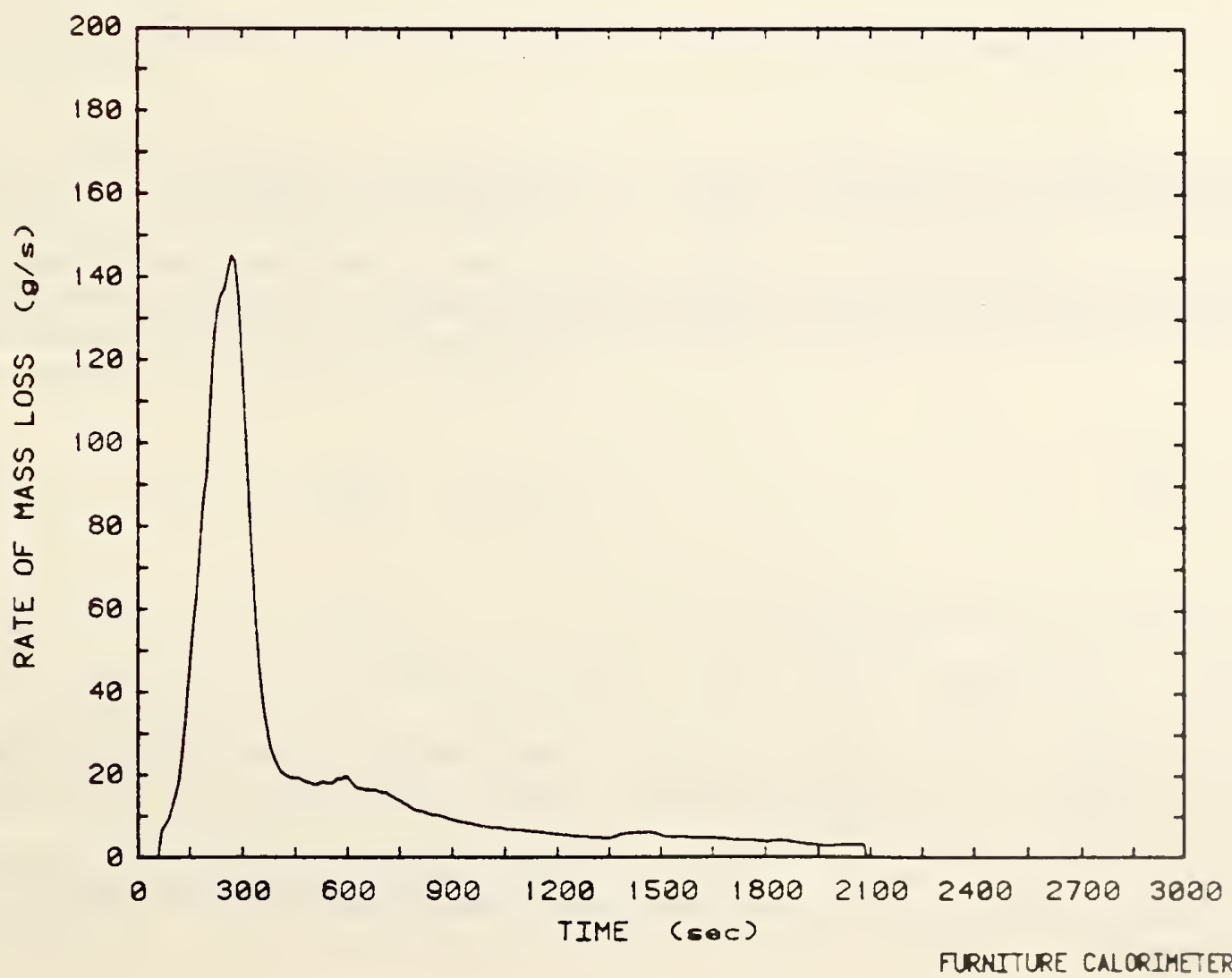

Figure B4. Rate of mass loss plot for sofa with "California foam" cushions [3]. 


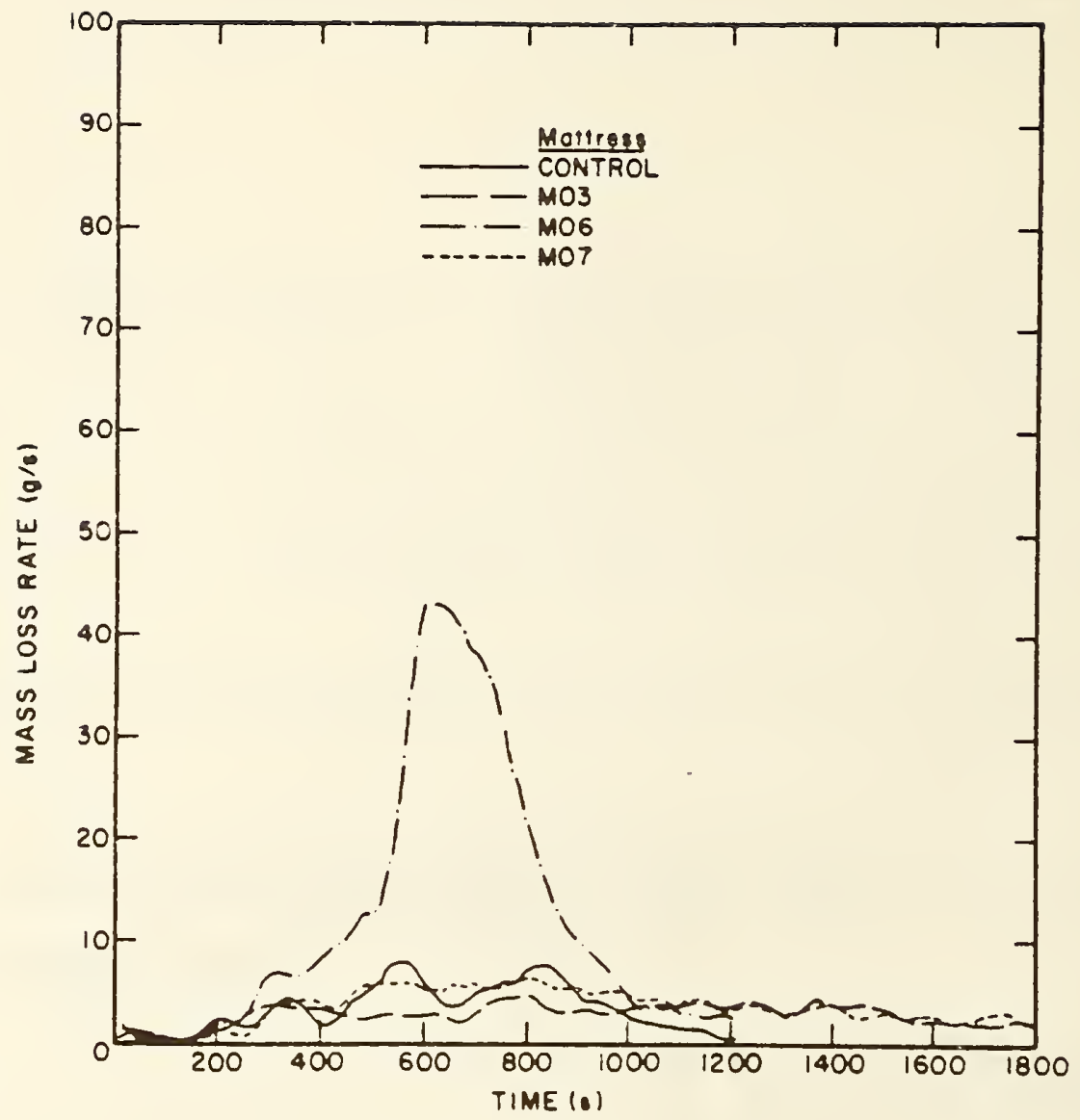

Figure B5. Weight loss for cotton and mixed fiber core specimens [4].

A review of data from furniture fires [3] indicates that for polyurethane foam chairs, Eq. (3) may also produce useful estimates for $t>170 \mathrm{~s}$.

Modak and Croce [6] studied the burning of polymethyl methacrylate (PMMA) plastic pool fires and found that experimentally measured burning rates per unit area, $\dot{m}{ }^{\prime}(t)$, at time $t$ after ignition were correlated by the equation:

$$
\frac{\dot{\mathrm{m}}_{s} "-\dot{\mathrm{m}}^{\prime \prime}(t)}{\dot{\mathrm{m}}_{\mathrm{S}}{ }^{\prime}-\dot{\mathrm{m}}_{\dot{i}}}=e^{-t / \tau}
$$

Therefore $\dot{\mathrm{m}}^{\prime \prime}(t)$ can be estimated by,

$$
\dot{\mathrm{m}}^{*}(t)=-\left[e^{-t / \tau}\left(\dot{m}_{s}^{*}-\mathrm{m}_{\dot{i}}^{*}\right)-\dot{\mathrm{m}}_{\mathrm{s}}^{*}\right]
$$

where $\dot{\mathrm{m}}_{\ddot{q}} \cong 4 \mathrm{~g} / \mathrm{m}^{2} \mathrm{~s}$ is the average burning rate per unit area; $\dot{\mathrm{m}}_{\mathrm{s}}$ is the steady burning rate, and $\tau$ is the characteristic "gasification time" to reach steady state.

Table Bl contains data that can be used for calculating m $^{\prime}(t)$ for various size pools of PMMA. 
Table Bl

Results for PMMA Pool Fires of Varying Scale [6]

\begin{tabular}{|c|c|c|c|}
\hline $\begin{array}{c}\text { Pool area } \\
m^{2}\end{array}$ & $\begin{array}{c}\text { Measured } \\
\text { steady } \\
\text { burning rate } \\
\text { per unit area } \\
\dot{\mathrm{m}}_{\mathrm{s}} \\
\left(\mathrm{g} / \mathrm{m}^{2} \mathrm{~s}\right)\end{array}$ & $\begin{array}{c}\text { Gasification } \\
\text { time } \\
\text { parameterb } \\
\tau \\
\text { (s) }\end{array}$ & $\begin{array}{c}\text { Radiative } \\
\text { fraction o } \\
\text { total hea } \\
\text { release ra } \\
x \\
(-)\end{array}$ \\
\hline $2.58 \times 10^{-3}$ & 4.6 & NA & $0.28^{c}$ \\
\hline $5.81 \times 10^{-3}$ & 5.6 & $\mathrm{NA}$ & $0.32^{c}$ \\
\hline 0.0232 & $7.7^{b}$ & 3448 & $0.32^{c}$ \\
\hline 0.0523 & $9.0^{b}$ & 1587 & 0.42 \\
\hline 0.0929 & $17.4^{b}$ & 1136 & 0.42 \\
\hline 0.3716 & 18.0 & 500 & 0.42 \\
\hline 0.5806 & 18.25 & 357 & 0.42 \\
\hline 1.4865 & 20.0 & 118 & 0.42 \\
\hline
\end{tabular}

best fit.

$\mathrm{C}_{\text {Varied with time. }}$

NA not available.

BURNING RATES FOR LIQUID POOL FIRES. In order to estimate burning rates for liquid pool fires, data were taken from a report by Burgess, et al. [7]. Their study shows the burning rate for a number of liquid fuels is a function of pool diameter. But for large diameter pools, flame radiation dominates and a maximum burning rate is achieved. Empirically they suggest that this maximum burning rate can be found by

$$
\dot{\mathrm{m}}_{\max }^{\ddot{*}}=6.5 \times 10^{-3} \frac{\mathrm{cm}}{\mathrm{min}} \rho \Delta \mathrm{H}_{\mathrm{c}} / \Delta \mathrm{H}_{\mathrm{v}}
$$

where $\rho$ is the liquid density

$$
\begin{aligned}
& \Delta H_{c} \text { is the heat of combustion, and } \\
& \Delta H_{v} \text { is the heat of vaporization. }
\end{aligned}
$$

Some specific results are given below in Table B2 for pool diameters greater than $1.5 \mathrm{~m}$. 
Table B2

Burning Rates for Liquid Pool Fires.

\section{Linuid}

$\mathrm{n}$-Hexane

Benzene

UDMH

Methanol

Gasoline

Diesel fuel $\dot{\mathrm{m}}_{\max }$

$\left(\mathrm{g} / \mathrm{m}^{2} \mathrm{~s}\right)$

76.9

87.9

44.3

15.8

45.

43. $x_{r}$, Elame radiation fraction

(\%)

\section{2}

35

24

15

$-$

\section{Radiant Heat Flux to a Target}

After the initial fire has been defined, it is important to know something about the heat radiated from the source that could cause secondary ignitions. A technique discussed by Modak [8] will be used to estimate radiant flux. This method is depicted in the sketch below and is detailed in Eq. (7).

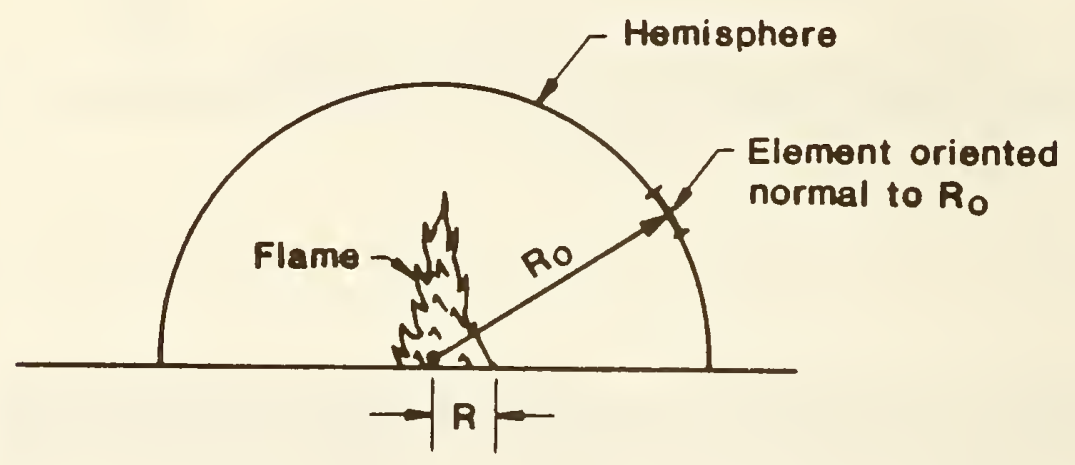

Figure B6. Fire radiant heat transfer to a target.

The incident heat flux at a target can be approximated as

$$
\dot{\mathrm{q}}_{\mathrm{O}}^{\prime \prime} \cong \mathrm{P} / 4 \pi \mathrm{R}_{\mathrm{O}}^{2}
$$

where $P$ is the total radiative power output of the flame. $P$ can be represented as $x_{r} \dot{Q}$ where $\chi_{r}$ is the radiative fraction and $\dot{Q}$ is total energy release rate. Usually $\chi_{r}$ ranges from 20 to 45 percent for many fuels. For a typical pool fire Modak [8] finds that the above formula is $>90$ percent accurate when $R_{0} / R>4$. At $R_{0} / R=2$, the approximation is about 80 percent correct. 
Since burning rates and thermal radiation to targets have been defined, a third physical phenomenon relating to flame geometry must be considered. Flame height is an important characteristic which provides information needed Eor estimating heat transfer to a room's ceiling and other structures that may be located above a fire. It has been shown by McCaffrey [9] that flame height, $Z_{f}$, is related to the total energy release rate, $Q$, and the diameter, $D$, of the fire base. This is illustrated in Figure $B 7$ which is taken from a report by Zukoski, et al. [10].

For flame heights where $\left(Z_{f} / D\right)>2$, Zukoski suggested the following equation which provides a reasonable estimate:

$$
z_{f}=\left[0.23 \mathrm{~m} / \mathrm{kW}^{2 / 5}\right] Q^{2 / 5} \text {, }
$$

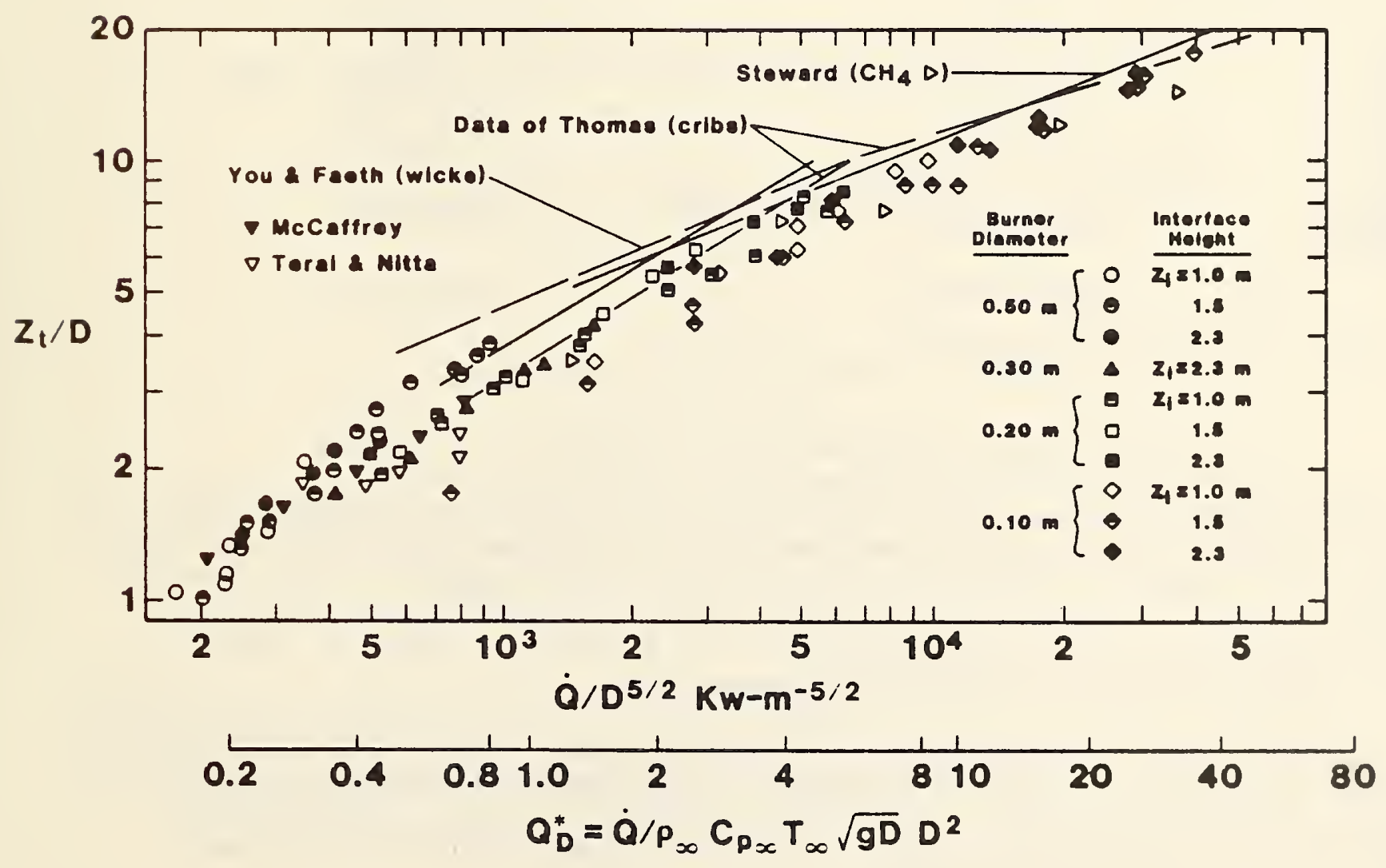

Figure B7. Flame height dependence on heat release parameters [10].

or use Figure B7 directly.

In addition, work reported by Hasemi and Tokunaga [11] for a 0.5 m diameter burner showed that the height of the continuous flame region could be est1mated by 


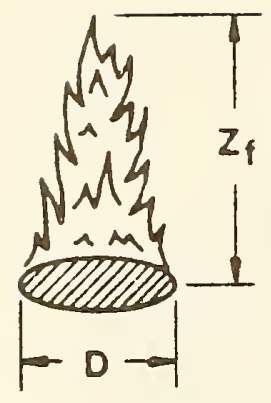

$$
z_{f \min }=\left(0.11 \mathrm{~m} / \mathrm{kW}^{2 / 5}\right) \dot{Q}^{2 / 5}
$$

and the height to the flame tip could be estimated by

$$
Z_{f \max }=\left(0.21 \mathrm{~m} / \mathrm{kW}^{2 / 5}\right) \dot{Q}^{2 / 5}
$$

Figure B8a. For Open Flames

These results are consistent with Eq. ( 8 ) and Figure B7, but explicitly address the variation of the flame structure from a continuous luminous region to a region above which is intermittent flames terminating at the flame "tip".

Their work also provides equations that are useful in estimating flame heights in a corner fire scenario. See Figure B8b. Equations (11) and (12) provide these estimates.

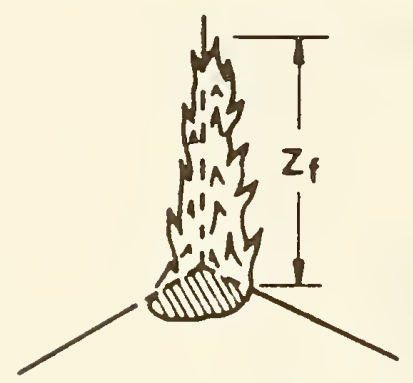

$$
\begin{aligned}
& z_{f \min }=\left(0.075 \mathrm{~m} / \mathrm{kW} /{ }^{2 / 5}\right) Q^{3 / 5} \text { for the continuous flame } \\
& z_{f \max }=\left(0.118 \mathrm{~m} / \mathrm{kW}^{2 / 5}\right) \dot{Q}^{3.5} \text { for the flame tip }
\end{aligned}
$$

Fig. B8b. Corner Fire Scenario.

\section{Radial Flame Impingement and Heat Flux to a Ceiling}

Now that flame height has been estimated, it is possible to estimate radial Elame impingement on a ceiling and heat flux at a ceiling using equations offered in a report by You and Faeth [12]. When the height of a free burning flame exceeds the height of the ceiling, flame impingement would occur for that fire burning in a confined geometry. That effect is shown in Figure B8 where $H_{R}$ gives the radial flame impingement length.

It has been found [12] that the height $\left(\mathrm{H}_{\mathrm{f}}\right)$ of a free burning fire in the open generally exceeds the sum of the ceiling height ( $H$ ) and impingement length $\left(H_{R}\right)$ under these conditions. Thus, for a given fire energy release rate $Q$, once $\mathrm{H}_{\mathrm{f}}$ exceeds the ceiling height, the radial flame extension can be estimated from the following formulae.

For a ceiling with no side walls,

$$
\frac{\mathrm{H}_{\mathrm{R}}}{\mathrm{D}}=0.5\left[\left(\mathrm{H}_{\mathrm{f}}-\mathrm{H}\right) / \mathrm{D}\right]^{0.96}
$$


and Eor a ceiling with side walls,

$$
\frac{{ }^{H_{R}}}{D}=0.69\left[\left(\mathrm{H}_{\mathrm{f}}-\mathrm{H}\right) / \mathrm{D}\right\rceil^{0.89}
$$

where $\mathrm{D}$ is the fire base diameter and $\mathrm{H}_{\mathrm{f}}$ can be found from Eq. (8). (Here $Z_{\mathrm{F}}$ and $\mathrm{H}_{F}$ are the same; since we have not attempted to unify our notation but have retained the notation of the original source.)

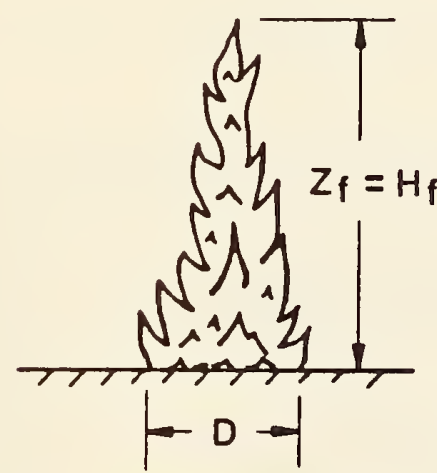

(open flame)

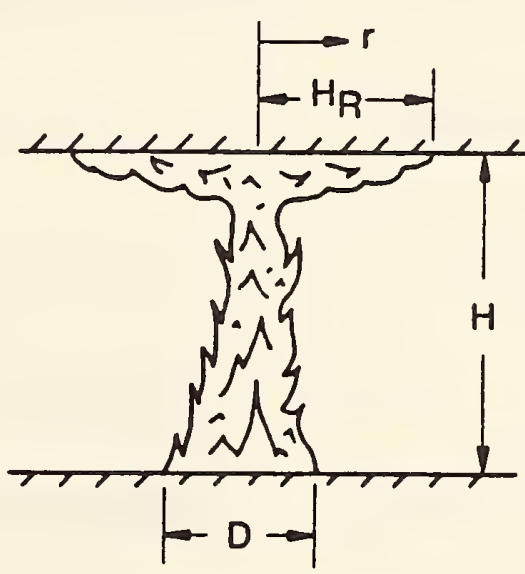

(confined flame)

Figure B9. Flame length and geometric environment.

From the work of You and Faeth [12] an estimate of the incident (primarily convective) heat flux to the ceiling just above the fire can be found. This stagnation point heat flux $\dot{q} "$ is determined from the correlation:

$$
\dot{\mathrm{q}} " \mathrm{H}^{2} / \dot{\mathrm{Q}}=31.2 \mathrm{Pr}^{-3 / 5} \mathrm{Ra}^{-1 / 6}
$$

where $H$ is the ceiling height and $\dot{Q}$ is the fire energy release rate. The equation was established for a Prandtl number of $\operatorname{Pr}=0.7, \mathrm{H}_{\mathrm{f}} / \mathrm{H}<1.5$, $109<\mathrm{Ra}<1014$, and where flame radiative heat flux is small. The Rayleigh number, Ra, is defined as $\left(g B / \rho c_{p} \nu^{3}\right)=7.9 \times 10^{12} \mathrm{~kW}^{-1} \mathrm{~m}^{-2}$.

$$
\dot{q} "=0.28 Q^{5 / 6} H^{-7 / 3}
$$

where $Q$ is in $\mathrm{kW}$ and $\mathrm{H}$ is in $\mathrm{m}$. Much of the data correspond to low Ra, or small scale so this formula may yield perhaps low estimates on extrapolation to large scale. For $\mathrm{H}_{\mathrm{f}} / \mathrm{H}>1.5$, they found the stagnation point heat flux to decrease significantly from the above formula. For large flames, flame radiation should be added, and also hot layer gas and surface radiation should be included after the room becomes hot $\left(>300^{\circ} \mathrm{C}\right)$. 
At this point in the calculation process, the basic fire has been characterized, and it is time to direct attention to changes in environmental conditions which result from the fire. In this section, estimates will be made on smoke filling time for a room. The "filling time", $t_{f}$, can be estimated as follows, i.e., $t_{f}=$ time for the layer to reach a door soffit (see Figure BlO) or a floor leak as in the case examined by Zukoski [13]. Figure Bll illustrates the dependence of ceiling layer height on time and heat input rate. For these results, heat loss from the smoke layer is neglected, and the room filling times are somewhat shorter than would be expected in a real fire. The governing equation and notation from Zukoski's analysis [13] are described below.

\section{Smoke Filling Time}

$$
\frac{\mathrm{dy}}{\mathrm{dt}}+\mathrm{Q}^{*}+\alpha\left(\mathrm{Q}^{*}\right)^{1 / 3} \mathrm{y}^{5 / 3}=0
$$

where

$$
\begin{aligned}
& y=Z / H \quad \text { nondimensional height of smoke layer interface } \\
& \tau=t \sqrt{\mathrm{g} / \mathrm{H}}\left(\mathrm{H}^{2} / \mathrm{S}\right) \quad \text { nondimensional time } \\
& t=t i m e \\
& \mathrm{~g}=\text { acceleration of gravity } 9.8 \mathrm{~m} / \mathrm{s}^{2} \\
& \mathrm{H}=\text { room height } \\
& S=f l o o r \text { area of the room } \\
& Q^{*} \equiv \dot{Q} /\left(\rho_{\infty} T_{\infty} C_{p} \cdot \sqrt{g H} \cdot H^{2}\right) \text { which is a nondimensional fire heat } \\
& \text { input parameter. } \\
& Q=\text { energy release rate of the fire } \\
& \rho_{\infty}=\text { density of the air in room } \\
& C_{p}=\text { specific heat at constant pressure for air } \\
& \alpha=1 / 5.4 \text {, the mass entrainment coefficient }
\end{aligned}
$$




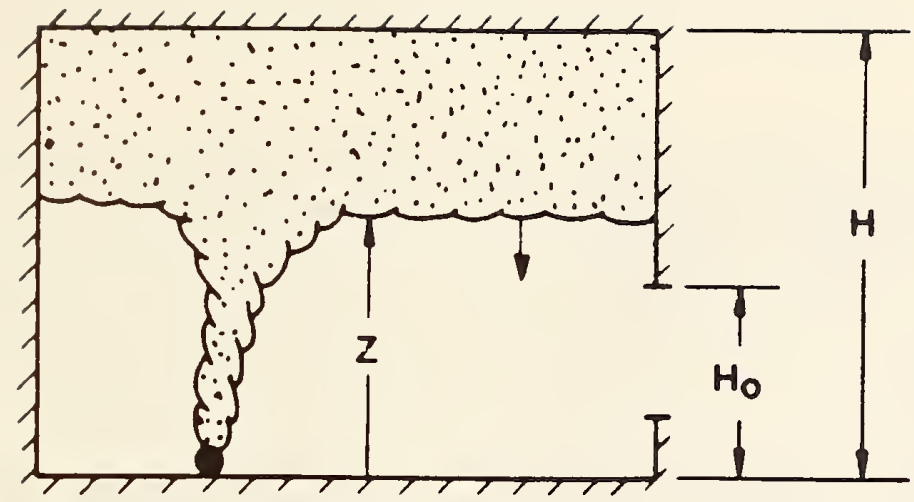

Figure Bl0. Room smoke filling model.

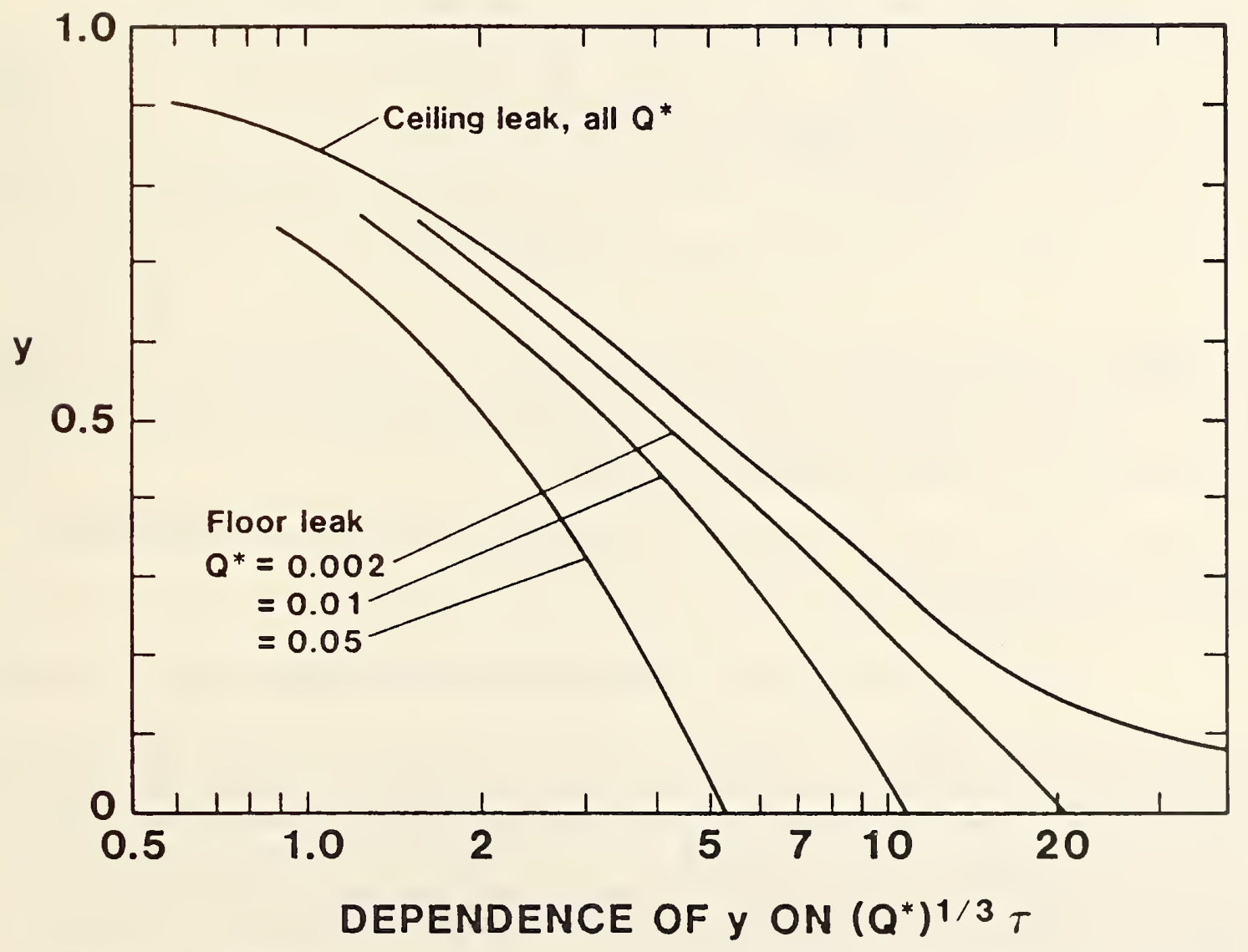

Figure B11. Ceiling layer height versus time and heat input rate [13]

In Eq. (16), if $Q^{*}$ is small, $<0.01$

$$
y \approx\left[1+\left(\frac{2 \alpha}{3}\right)\left(Q^{*}\right)^{1 / 3} \tau\right]^{-3 / 2}
$$


and if $Q^{*}$ is large, $>0.4$,

$$
y \approx 1-Q^{*} \tau
$$

To solve for $t_{f}$ when $Q^{*}<0.01$, Eq. (20) is solved for $\tau$,

$$
\tau \approx \frac{\frac{1}{y}^{2 / 3}-1}{\frac{2 \alpha}{3} Q *^{1 / 3}}
$$

The time $t_{f}$ to fill to a specific position $y$ is then found by inverting Eq. (18) as follows:

$$
t_{\mathrm{f}}=\frac{\tau}{\sqrt{\mathrm{g} / \mathrm{H}}\left(\mathrm{H}^{2} / \mathrm{s}\right)}
$$

Smoke layer height from the floor, Z, can be calculated by Eq. (23b)

$$
Z=H 1+\frac{2 a}{3} \frac{\dot{Q}}{\rho_{\infty} T_{\infty} C_{P} \sqrt{g H} H^{2}}+\sqrt{g / H} \frac{H^{2}}{S}-3 / 2
$$

To solve for $t_{f}$ when $Q^{*}>0.4$, Eq. (2l) is solved for $\tau$,

$$
\tau \approx \frac{1-y}{Q^{*}}
$$

and then solved for $t_{f}$ again using Eq. (23).

In cases where $0.01<Q^{*}<0.4$ one must integrate the ordinary differential Eq. (16) or use Figure B10.

\section{Time to Carbon Monoxide Hazard With Smoldering Fires}

The previous section presented a method for estimating smoke filling in a room when an opening is present in a wall or a leak is near the floor. This section uses smoke filling time and other data to estimate hazard time related to carbon monoxide exposure which results from a smoldering chair. Equations used in this estimate are taken from a report by Quintiere et a1. [14]. In that analysis the smoke filling time is calculated using Eqs. (16) through (23) where the value of $Q$ is estimated by

$$
Q=\text { in } \Delta H
$$

where $\dot{m}$ is the rate of mass loss due to smoldering and $\Delta H$ is the heat of reaction for the smoldering process. Here we adopt a simpler procedure based on that study to allow ease in making first order estimates.

It is shown that in could be approximated for a smoldering fire in polyurethane or cotton using 
where $c=0.206 \mathrm{gm} \mathrm{min}^{-2}$ for polyurethane and $c=0.33 \mathrm{gm} \mathrm{min}^{-2}$ for cotton, and $t$ represents time in minutes. The heat of reaction for polyurethane is $\Delta H=15 \pm 8 \mathrm{kJg}^{-1}$ and cotton is $\Delta H=11 \pm 1 \mathrm{kJg}^{-1}$. These results were only for slabs of particular samples of cotton and polyurethane. Moreover the smoldering rate of an upholstered chair composed of cotton and polyurethane initially grew quadratically with time, then remained constant for the next hour. Thus, Eq. (26) with the constants given can only be taken as a rough estimate for $\dot{m}$. It was, however, found that the mass generation rate of $c 0$ could be taken as proportional to the mass loss rate in smoldering, and that constant $Y$ was estimated as about $0.1 \mathrm{~g} \mathrm{CO} / \mathrm{g}$ fuel lost for both the polyurethane and cotton samples discussed above. Thus for those cases the CO generation rate was estimated as

$$
\dot{\mathrm{m}}_{\mathrm{co}}=\text { rct. }
$$

As a first estimate we will use Eq. (27) and consider a well-mixed closed volume (V) in which the smoldering takes place. The more general stratified case with "filling" was discussed in ref. [14], but in actuality the dispersal of smoldering products is not so well defined. Consequently a uniformly mixed volume is reasonable alternative. For this case the mass fraction of co in the volume defined to be $Y$ is given by

$$
\frac{d Y}{d t}=\frac{r^{m}}{\rho V}
$$

where $\rho$ is the gas density. Finally adopting a critical dose of $4.5 \%$ CO-min for human incapacitation as suggested by the work of Stuart et al [14], and since the dose $D$ can be expressed as $D=f^{t}$ Ydt it follows from Eqs. (26-28)
that

$$
D=\frac{c y t^{3}}{6 \rho V} .
$$

where $D=0.045$ min for the critical dose, the hazard time can be estimated.

Rewriting this equation to solve for $t$

$$
t=\left(\frac{6 D \rho V}{c \gamma}\right)^{1 / 3}
$$

where

$$
\begin{aligned}
& V=\text { volume of the room } \\
& \rho=\text { density of the gas } \\
& c=\text { values shown above for polyurethane and cotton } \\
& \gamma=\text { the mass fraction of } C 0 \text { produced per smoldering mass loss of fuel }
\end{aligned}
$$

For example, with a cotton sample $t=25.3 \mathrm{~V}^{1 / 3}$ where $t$ is in minutes and $\mathrm{V}$ is $\mathrm{m}^{3}$. The time to critical dose is finally calculated using Eq. (30).

It should be emphasized that the above analysis is very approximate and not generally applicable to all smoldering conditions. It is only offered as a first-order of magnitude estimate. 


\section{Temperature Rise of Hot Gases in a Compartment}

A second environmental condition that requires consideration in a room fire is the resulting temperature rise. This has been studied and correlated by several different investigations. The method for estimating temperature rise, $\Delta \mathrm{T}$, here comes from reports by Quintiere [15] and McCaffrey, et al. [10]. This model considers temperature rise in compartments containing single or multiple wall vents, and the venting action is created only by natural convection. Figure BI2 describes a compartment example and defines some parameters.
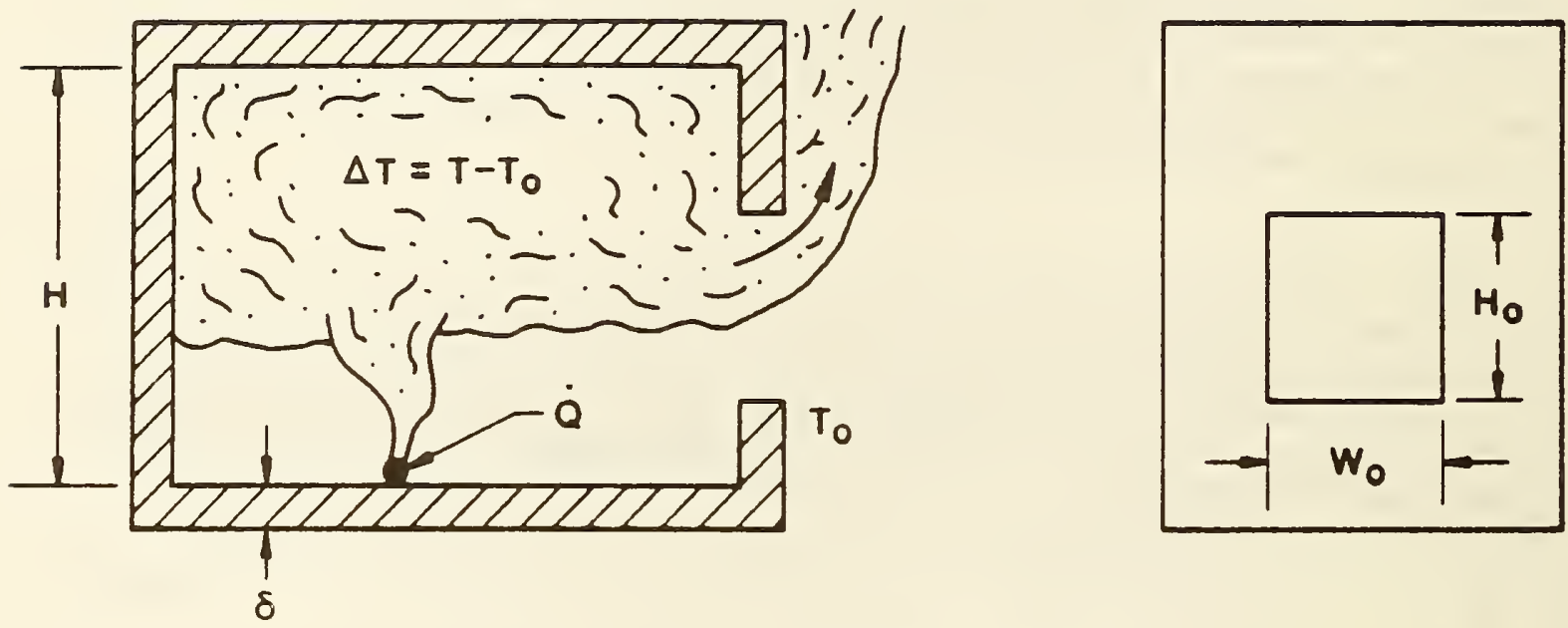

Figure B12. Compartment example.

The equation used for making this estimate of compartment gas temperature rise is

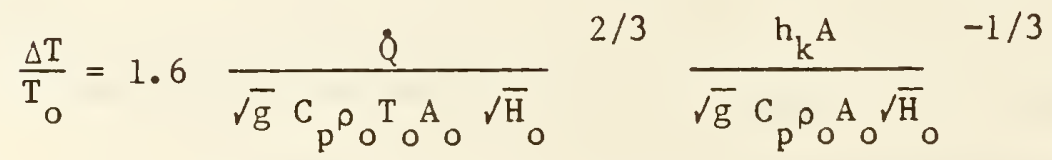

where $\quad T_{0}=$ initial or ambient air temperature

$$
\begin{aligned}
& \mathrm{Q}=\text { rate of energy release } \\
& \mathrm{g}=\text { acceleration of gravity } 9.8 \mathrm{~m} / \mathrm{s}^{2} \\
& \mathrm{C}_{\mathrm{p}}=\text { specific heat of air at constant pressure } \\
& \rho_{\mathrm{O}}=\text { density of ambient air } \\
& \mathrm{A}_{\mathrm{O}}=\mathrm{W}_{\mathrm{O}} \mathrm{H}_{\mathrm{O}} \text {, vent area } \\
& \mathrm{W}_{\mathrm{O}}=\text { horizontal vent dimension } \\
& \mathrm{H}_{\mathrm{O}}=\text { vertical vent dimension }
\end{aligned}
$$




$$
\begin{aligned}
& h_{k}=\sqrt{k \rho c / t}, t \leq t_{p} \text { effective enclosure } \\
& k / \delta, \quad t>t_{p} \text { conductance } \\
& k=\text { thermal conductivity of the enclosure structure } \\
& \rho \quad=\text { density of the enclosure structure } \\
& c=\text { specific heat of the enclosure structure } \\
& \delta=\text { enclosure material thickness } \\
& t=\left(\frac{\rho c}{k}\right)\left(\frac{\delta}{2}\right)^{2}, \text { thermal penetration time } \\
& A=\text { total surface area }
\end{aligned}
$$

Both $h_{k} A$ and $A_{0} \sqrt{H_{O}}$ should be summed for multiple structural materials and openings, respectively. The procedure for addressing multiple features is elaborated on in refrence [15].

\section{Ventilation Flow Rate}

Now that methods have been presented for estimating burning rates and $\Delta \mathrm{T}$ in a fire compartment, it is time to consider ventilation flow rates in the fire. It was pointed out by Steckler, et al. [17] that the flow of air and gases in room fires has a significant influence on the development of a fire. As a fire develops, the air and gas flow rates control compartment temperature and heat transfer which then affects the rate of fire growth. When a compartment fire reaches a fully involved state, the air flow rate usually controls the fire, and the fire is then considered to be ventilation controlled. The mass flow rate of air and gases will be estimated first in this section, and ventilation limit conditions will be examined later.

In order to further understand the terminology of vent flow refer to Figure B13. Under natural convection conditions and after the hot gases fill the compartment and spill out of the vent, the flow will be countercurrent at the vent. Air will enter at a rate $\dot{\mathfrak{m}}_{i}$ and combustion products will flow out at a rate $\dot{m}$. These flows result from pressure differences $(\Delta p)$ set up at the vent due to ${ }^{\circ}$ the differences in compartment and ambient gas temperatures. At the flow reversal point in the vent, the $\Delta p$ is zero and this position is termed the neutral plane. The flow rates depend on the fuel mass release rate $\dot{m}_{f}$, the height of the neutral plane $x_{2}$, the height of the hot gas layer $x_{1}$, 1 ts temperature $\mathrm{T}$, and the vent dimensions $\mathrm{H}_{0}$ and $\mathrm{W}_{0^{\circ}}$. In general the vent equations are coupled nonlinear algebraic equations which we will avoid solving, but suggest the approximate procedure below. 


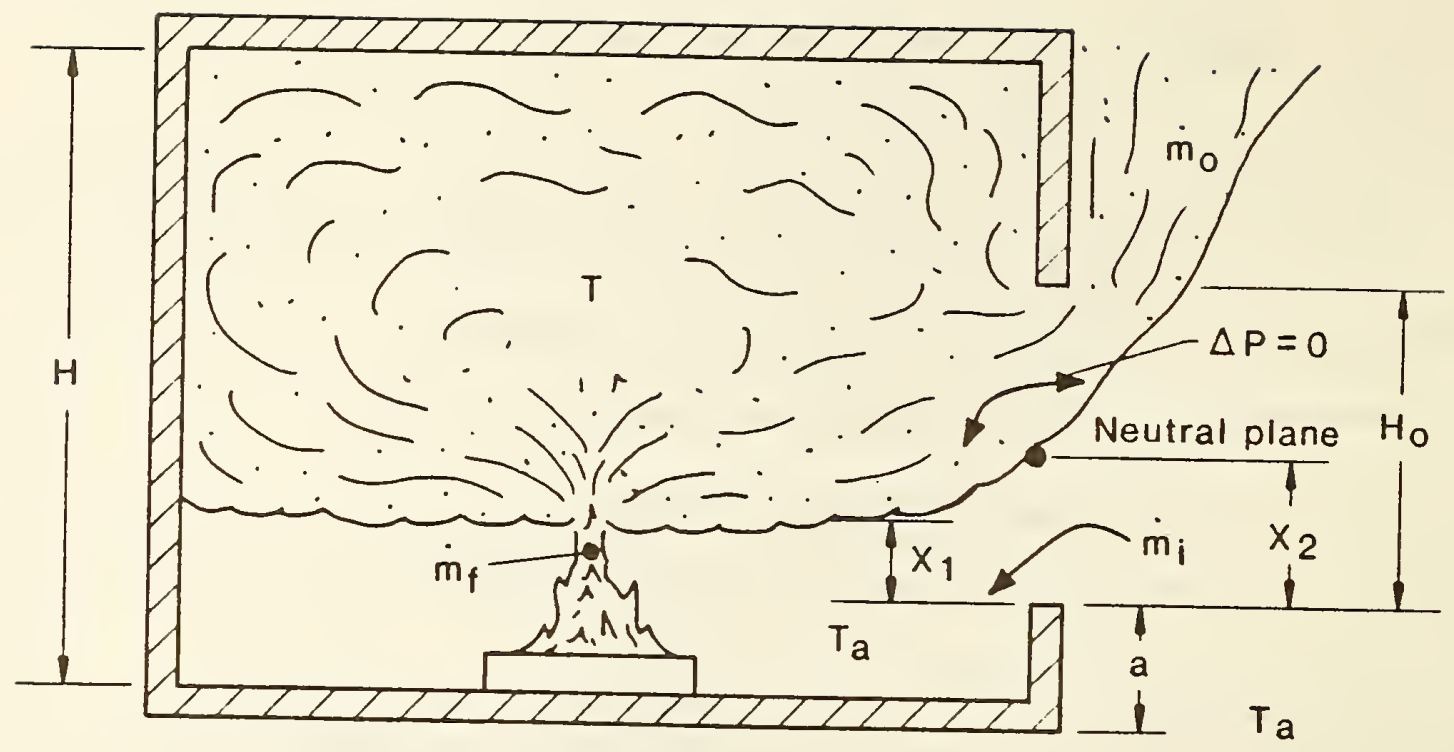

Figure B13. Sketch of compartment ventilation problem.

To make this ventilation flow rate estimate, it is necessary to assume a free burning condition. The first step in making this estimate is to calculate a fuel mass burning rate, $\dot{m}_{f}$, with one of the methods found in section 2, and then calculate the compartment gas temperature by the formula presented in section 8. At this point the dimensionless mass flow rate $M_{0}$ can be calculated [18] using,

$$
M_{0}=\left[\psi^{1 / 2} /(1+\psi)\right]\left(1-y_{2}\right)^{3 / 2}
$$

where $\quad \psi \equiv \frac{T-T_{a}}{T_{a}}$

and $y_{2}=x_{2} / H_{0}$ can be estimated as 0.5 to 0.6 for $\psi \leq 1$ and for wellventilated fires where $\dot{\mathrm{m}}_{\mathrm{f}} / \dot{\mathrm{m}}_{i}$ is small as found in reference [18]. For the case of larger $\psi$ and $\dot{\mathrm{m}}_{\mathrm{f}} / \mathrm{m}_{i}$ not small, the neutral plane can be estimated from the work of Kawagoe and Sekine [19] or from reference [18] in which $x_{1}=0$ :

$$
y_{2}=\frac{1}{1+\frac{T}{T_{a}}{ }^{1 / 3} 1+\frac{\dot{\mathrm{m}}_{f}}{\dot{\mathrm{m}}_{\mathrm{i}}}} 2 /
$$

This will yield the lower limit for $y_{2}$ when the hot layer tends to the floor and the enclosure tends toward a uniform gas temperature. Then mass flow rate out, ino, can be calculated using,

$$
\dot{\mathrm{m}}_{\mathrm{O}}=\frac{2}{3} \mathrm{M}_{\mathrm{O}} \mathrm{C}_{\rho_{\mathrm{a}}} \sqrt{2 \mathrm{~g}} \mathrm{w}_{\mathrm{O}} \mathrm{H}_{\mathrm{O}}^{3 / 2}
$$


$\rho_{a}=$ density of ambient gas surrounding area

$g=$ acceleration of gravity $\left(9.8 \mathrm{~m} / \mathrm{s}^{2}\right)$

$W_{0}=$ opening width

$\mathrm{H}_{\mathrm{O}}=$ opening height

The mass inflow rate of air, $\dot{\mathrm{m}}_{i}$, can be calculated by,

$$
\dot{m}_{i}=\dot{m}_{0}-\dot{m}_{\mathrm{f}}
$$

for which steady flow conditions have been assumed. Of course if $\dot{\mathrm{m}}_{\mathrm{f}} / \stackrel{\circ}{\mathrm{m}}_{\mathfrak{i}}$ is found to be large, then iteration is required in the above computations. Moreover the ratio $\dot{\mathrm{m}}_{\mathrm{f}} / \dot{\mathrm{m}}_{i}$ should be compared with the mass stoichiometric fuel to air ratio to examine whether the fire is ventilation limited. We will return to this point shortly.

\section{Does Flashover Occur?}

The methods presented have provided a basis for predicting the fire environment up to the point of rapid transition in fire behavior. This critical point is called "flashover", and it has been defined in many different ways. A paper by Thomas, et al. [20] describes five different processes or combinations of processes that could lead to flashover. It is pointed out that flashover usually results in a sharp increase in room temperature and rate of energy release. Thomas shows that flashover is typically associated with compartment gas temperatures which range between $300-650^{\circ} \mathrm{C}$. For the flashover estimates calculated in this paper it is suggested that a critical gas temperature rise of $500^{\circ} \mathrm{C}$ be selected. Thus for a given $Q(t)$ the formulae for $\Delta T$, given by Eq. (31), can be solved to find the time, $t$, at which $\Delta \mathrm{T}=500^{\circ} \mathrm{C}$ or the "flashover" time.

Alternatively, the condition for flashover with a constant energy release rate $Q$ follows from Eq. (31) in which $\Delta \mathrm{T}$ is set equal to $500^{\circ} \mathrm{C}$. That result is given as

$$
\dot{Q}=610\left(h_{k} A A_{0} \sqrt{\mathrm{H}_{0}}\right)^{1 / 2}
$$

for which $Q$ is in $\mathrm{kW}, \mathrm{h}_{\mathrm{k}}$ is in $\mathrm{kW} /\left(\mathrm{m}^{2} \mathrm{~K}\right), \mathrm{H}_{\mathrm{O}}$ in $\mathrm{m}$, and $\mathrm{A}$ and $\mathrm{A}_{\mathrm{O}}$ are $1 \mathrm{n} \mathrm{m}^{2}$. This result says that the energy release rate to cause "flashover" depends on the compartment thermal properties, its surface area, and the vent size.

\section{Mass Burning Rate in Ventilation Limited Fires}

After "flashover" or in fires where small openings restrict ventilation, the fire will probably become "ventilation limited." That is the supply of air to the room is less than that amount needed for stoichiometric burning of the available gasified fuel. It can also be defined as the point when the oxjgen level in the compartment reaches a low value (ideally zero) such that the reaction between fuel and oxygen ceases to produce products or proceeds very slowly. 
In general, the energy release rate of the fuel burning in the compartment, is given as

$$
\begin{aligned}
& \dot{\mathrm{Q}}=\dot{\mathrm{m}}_{\mathrm{f}} \Delta \mathrm{H} \text { for } \dot{\mathrm{m}}_{\mathrm{f}} / \stackrel{\mathrm{m}}{\mathrm{a}} \leq \gamma \leq \gamma \\
& (0.233) \dot{\mathrm{m}}_{\mathrm{a}} \Delta \mathrm{H} \text { ox } \text { for } \dot{\mathrm{m}}_{\mathrm{f}} / \stackrel{\circ}{\mathrm{m}}_{\mathrm{a}} \geq \gamma
\end{aligned}
$$

where

$$
\begin{aligned}
& \gamma \text { is the mass stoichiometric fuel to air ratio } \\
& \Delta \mathrm{H} \text { is the fuel heat of reaction } \\
& \dot{\mathrm{m}}_{\mathrm{a}} \text { is the air flow rate through the vent }
\end{aligned}
$$

and

$$
\begin{aligned}
& \Delta \mathrm{H}_{\mathrm{ox}} \text { is the heat of combustion per unit mass of oxygen and is taken } \\
& \text { as } 13 \mathrm{~kJ} / \mathrm{g} \text {. }
\end{aligned}
$$

The fire is termed "fuel-controlled" for $\mathrm{m}_{\mathrm{f}} / \mathrm{m}_{\mathrm{a}}<\gamma$, and the energy release rate depends on the fuel pyrolysis rate. Since the air flow rate is primarily controlled by vent size, the available air supply will reach the limit for combustion as $\dot{m}_{f}$ increases. Thus as the fire grows, the rate of energy release within the compartment will be governed solely by the air supply rate. The excess fuel will exit the compartment with combustion continuing in the vent flame. This limit condition in which the maximum possible energy release rate is achieved in the compartment roughly occurs when $\dot{\mathrm{m}}_{\mathrm{f}} / \dot{\mathrm{m}}_{\mathrm{a}}=\gamma$ and the fire is termed "ventilation-controlled" as long as $\dot{\mathrm{m}}_{\mathrm{f}} / \dot{\mathrm{m}}_{\mathrm{a}} \geq \gamma$. Fires are generally fuel-controlled before the occurrence of flashover, and ventilationcontrolled afterwards [20].

In order to estimate the point of transition to ventilation control, both the fuel mass loss rate and the air supply rate must be known. The mass loss rate $\dot{\mathrm{m}}_{\mathrm{f}}$ depends on the enclosure conditions as illustrated qualitatively be low:

$$
\dot{\mathrm{m}}_{\mathrm{f}} \approx \dot{\mathrm{m}}_{\mathrm{fo}} \frac{\mathrm{Y}_{\mathrm{O}}}{0.233}+\frac{\dot{\mathrm{q}}_{\mathrm{e}}}{\mathrm{L}}
$$

where $\dot{\mathrm{m}}_{\mathrm{fo}}$ - is the free burning value

$\mathrm{Y}_{\mathrm{O}_{2}}$ - is the local oxygen concentration around the combustion region
within the enclosure $q_{e}$ - is the net heat transfer rate from the enclosure to the fuel

and L - is the fuel "heat of vaporization"

There is some evidence from ful1-scale experiments [14] that up to flashover or shortly before, the mass loss rate in an enclosure is nearly equal to its free burn value. After flashover, the mass loss rate will differ distinctly from its free-burn value. As a first estimate to assess whether the ventilation limit has been reached, the free burn mass loss rate should be compared with the maximum vent air flow rate. The latter can be estimated by using 
Eqns. ( 32 and 33) for $\dot{\mathrm{m}}_{\mathrm{f}} / \stackrel{\mathrm{m}}{\mathrm{i}}=0$ (i.e., small). Thus, the maximum possible vent air flow rate is for $\mathrm{T} / \mathrm{T}_{\mathrm{a}}>2$ :

$$
\dot{\mathrm{m}}_{\mathrm{a}, \max }=0.5 \mathrm{w}_{\mathrm{a}} \mathrm{H}_{\mathrm{o}}^{3 / 2}(\mathrm{~kg} / \mathrm{s})
$$

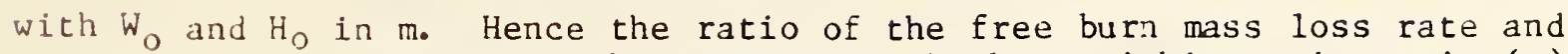
maximum air supply rate can be compared with the stoichiometric ratio $(\gamma)$.

After ventilation-limited conditions prevail, the mass loss rate of the fuel can not be directly computed. Nevertheless, results for wood crib fires have been empirically correlated $[19,21]$ to yield:

$$
\dot{m}_{\mathrm{f}} \cong 0.09 \mathrm{~W}_{\mathrm{O}} \mathrm{H}_{\mathrm{O}}^{3 / 2}(\mathrm{~kg} / \mathrm{s})
$$

with $W_{O}$ and $H_{O}$ in $m_{0}$ An estimate of the corresponding compartment gas temperature rise might also be made by computing the energy release rate from the maximum possible air flow rate Eq. (39). The result follows [15]:

$$
\Delta \mathrm{T}=896\left[\mathrm{~A}_{0} \sqrt{\mathrm{H}_{\mathrm{o}}} /\left(\mathrm{h}_{\mathrm{k}} \mathrm{A}\right)\right]^{1 / 3}\left({ }^{0} \mathrm{C}\right)
$$

where $A_{0}$ is the vent area $\left(m^{2}\right), H_{0}$ is the vent height (m), $h_{k}$ is the enclosure structure conductance $\left(\mathrm{kW} / \mathrm{m}^{2} \mathrm{k}\right)$ and $A$ is the structure surface area $\left(\mathrm{m}^{2}\right)$.

\section{Corridor Smoke Transfer and Filling}

Much work is currently being done to develop meaningful correlations and models for smoke transfer and filling in corridors. The interest in this subject springs from the need to predict changes in environmental conditions which occur throughout a building as a fire develops. This is of great importance to life safety. An estimate made for the smoke front velocity, $V_{f}$, will be taken from work in progress by Zukoski and Kubota [22]. Figure B14 displays the phenomenon of a smoke layer progressing along a corridor.

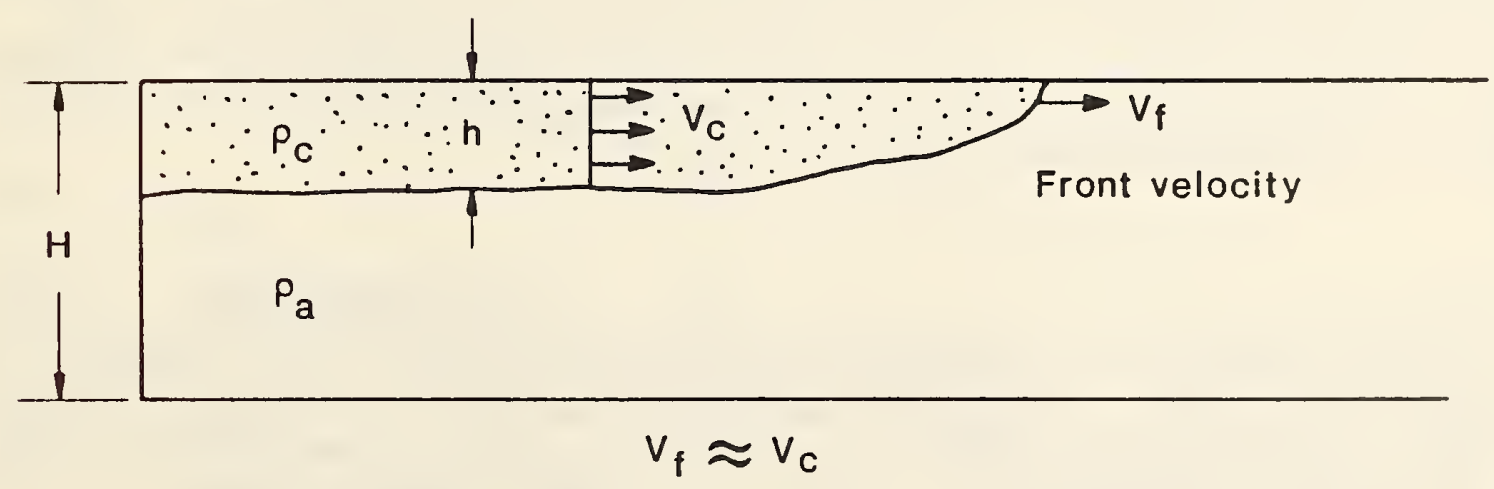

Figure B14. Corridor smoke transport.

From their preliminary analysis, we have extracted a result that represents an upper limit to the front velocity. This corresponds to the limiting case of the smoke layer filling half the corridor height and does not consider viscous effects which would retard the front speed. Thus a simple order of magnitude estimate is given below. 


$$
V_{\mathrm{f}} \approx 1 / 2\left[g\left(\frac{\rho_{\mathrm{a}}-\rho_{\mathrm{c}}}{\rho_{\mathrm{a}}}\right) \mathrm{H}\right]^{1 / 2}
$$

where $g$ acceleration of gravity,

$$
\begin{aligned}
& \rho_{a}=\text { density of ambient air, } \\
& \rho_{c}=\text { density of the corridor fluid, } \\
& H=\text { corridor height. }
\end{aligned}
$$

Density can be related to the fire room temperature provided no heat loss occurs. Thus from the ideal gas law:

$$
\frac{\rho_{a}-\rho_{c}}{\rho_{a}}=1-\frac{T_{a}}{T}
$$

where $\quad T_{a}=$ ambient temperature,

and $\quad T=$ gas temperature in fire room.

Subsequently the time $\left(t_{f}\right)$ for velocity front movement through a corridor is estimated by

$$
t_{f}=\frac{L}{V_{f}}
$$

where $\quad \mathrm{L}=$ corridor length

Smoke filling time for a closed corridor or adjacent space to a room can be estimated using the appropriate formulas selected from section 6 . But that approach would ignore the geometrical aspects of the room and corridor and their connecting doorway. It necessitates treating the corridor and room space as a single volume. Alternatively, work by Jones and Quintiere [23] suggest another approach. Figure Bl5 illustrates this smoke filling from a room fire to a closed adjacent space.

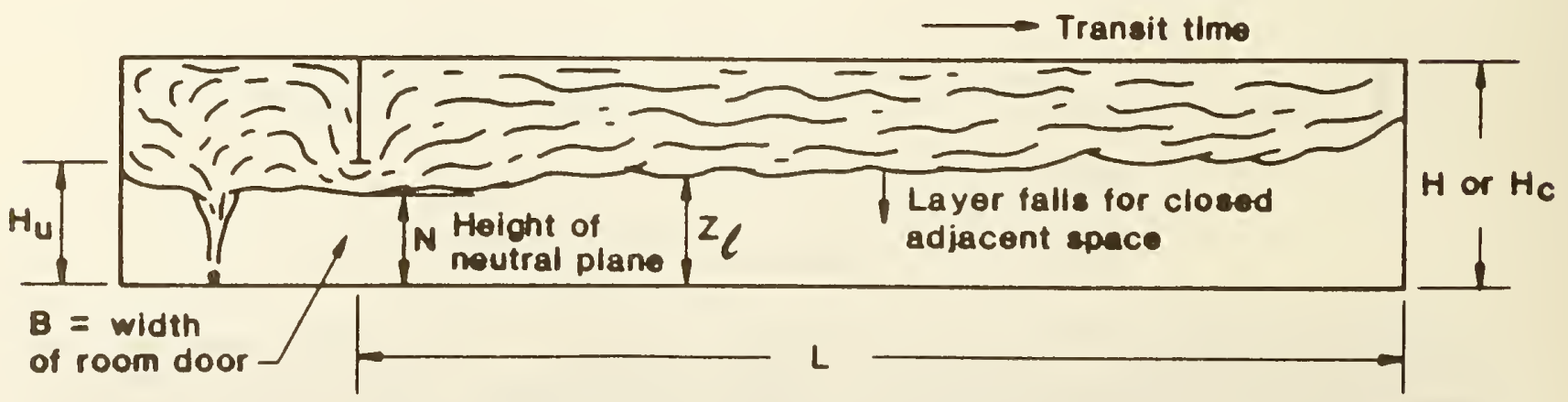

Figure B15. Smoke filling by a fire room to a closed adjacent space. 
In this method a scaling parameter, $\stackrel{\star}{\mathrm{P}}$, for the room door is considered, where

$$
\stackrel{\star}{\mathrm{P}}=B\left(\mathrm{H}_{\mathrm{u}}\right)^{3 / 2} /\left(\mathrm{H}_{\mathrm{C}}\right)^{5 / 2}
$$

where $B=$ width of the connecting door,

$$
\begin{aligned}
& \mathrm{H}_{\mathrm{u}}=\text { height of connecting door, } \\
& \mathrm{H}_{\mathrm{c}}=\text { height of corridor. }
\end{aligned}
$$

A correlation based on dimensionless variables was developed using both experimental and computational results. The conditions examined were a room and closed corridor of equal height $\left(H_{c}=2.32 \mathrm{~m}\right)$, a fixed room door height $\left(H_{n}=2.0 \mathrm{~m}\right)$, variable door widths $(0.13 \leq \mathrm{B} \leq 1.07 \mathrm{~m})$, and varying heat release rates $(25 \leq Q \leq 225 \mathrm{~kW})$. These conditions are representative of many building and developing fire conditions. The correlation is presented in Figure B16 which gives the dimenșionless filling time $\tau$ as a function of the fire and door parameters, $\bar{Q}$ and $\hat{\hat{P}}$, respectively. The time for filling was selected as the time for the smoke layer to descend to $1 \mathrm{~m}$ above the corridor floor. The dimensionless parameters are defined as follows:

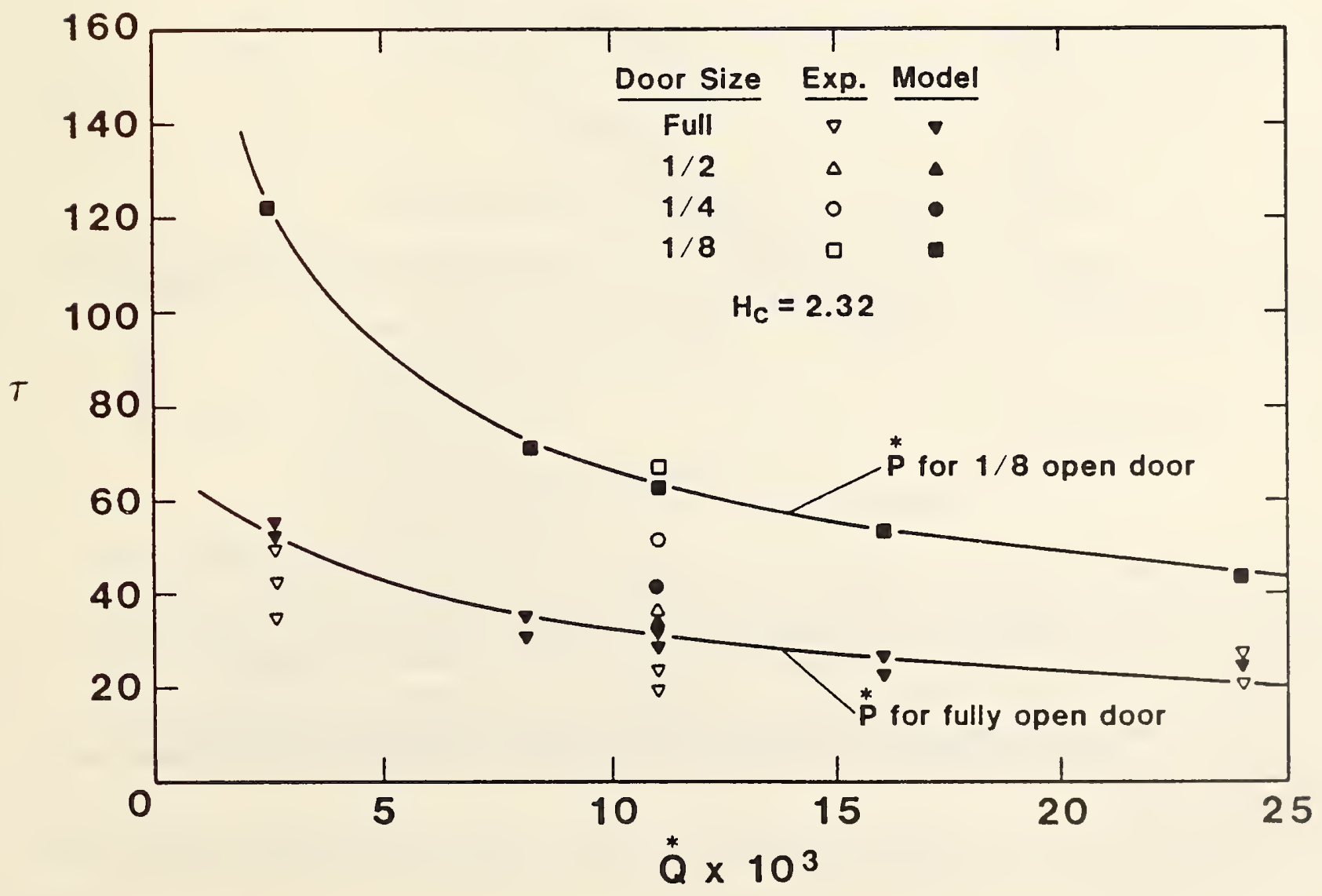

Figure B16. Dimensionless corridor smoke filling time [23] 
Q represents dimensionless heat release rate and is defined by the equation

$$
\stackrel{*}{Q}=Q /\left(C_{p_{a}}{ }^{*} \stackrel{*}{m}\right)
$$

where $Q$ = net heat release rate

$C_{p}=$ specific heat of air

$\mathrm{T}_{\mathrm{a}}=$ ambient temperature

and

$\stackrel{*}{m}=$ a dimensionless characteristic mass flow which is defined as

$$
\stackrel{*}{\mathrm{~m}}=\rho_{\mathrm{a}}\left(\mathrm{gH}_{\mathrm{c}}\right)^{1 / 2} \mathrm{H}_{\mathrm{c}}^{2}
$$

where

$$
\begin{aligned}
& \rho_{a}=\text { ambient density } \\
& g=\text { acceleration of gravity } \\
& H_{c}=\text { height of corridor. }
\end{aligned}
$$

The dimensionless time $\tau$ in Figure $B 16$ is given as

$$
\tau=t\left(\stackrel{*}{\mathrm{~m}} / \rho_{\mathrm{a}} \mathrm{AH} \mathrm{c}_{\mathrm{c}}\right)
$$

where $t=$ time $(s)$

and $\quad A=$ floor area for the corridor or adjoining space

To make an estimate ${ }_{\star}$ for filling time $t$, a $\dot{Q}$ is selected from which $\stackrel{*}{Q}$ is calculated. Using this $Q, t$ can be determined from Figure Bl6. Rearranging Eq. (47) to solve for $t$ yields

$$
t=\frac{\tau}{\left(\begin{array}{l}
* \\
m / \rho_{a} A H_{c}
\end{array}\right)}
$$

13. Smoke Concentration and Visibility

The production of smoke in fires is an important feature in evaluating life safety. Technically smoke might be considered to include particles, hot combustion products, and toxic gases. Here we will only address the particulate nature of smoke and its effect on visibility. Smoke obscures vision by the reduction of light transmission. Smoke may also reduce vision by irritating the eyes. In this section estimates for smoke concentration and visibility will be calculted for a closed system which consists of a room and adjacent space.

The production rate of smoke particles $\left(\dot{\mathrm{u}}_{\mathrm{s}}\right)$ in a fire can be expressed as

$$
\dot{\mathrm{m}}_{\mathrm{s}}=\mathrm{x}_{\mathrm{s}} \dot{\mathrm{m}}_{\mathrm{f}}
$$


where $x_{S}=$ fraction of particulate mass to fuel mass loss

$\dot{\mathrm{m}}_{\mathrm{E}}=$ fuel mass loss rate

The objective is to compute this production rate and relate it to visibility. Some background on needed data and applications can be found in reports by Quintiere [24], Babrauskas [25] and Tewarson [26]. An approximate relationship to predict visibility, defined to be $L_{v}$ the length one can see through smoke when no eye irritation is present, is given as

$$
L_{v}=k_{v} /(D / L)
$$

where $D / L$ is the optical density per unit path length

$\mathrm{k}_{\mathrm{v}}$ is a constant selected from Figure B 17 .

This relationship is derived from the results shown in Figure B17 [24] and is merely an approximate fit to those data. Of course the selected value for $k_{v}$ should be consistent with those results but could also represent a conservative design value. To apply Eq. (50) to a particular situation we must compute $(D / L)$ for that fuel and the configuration it burned in.

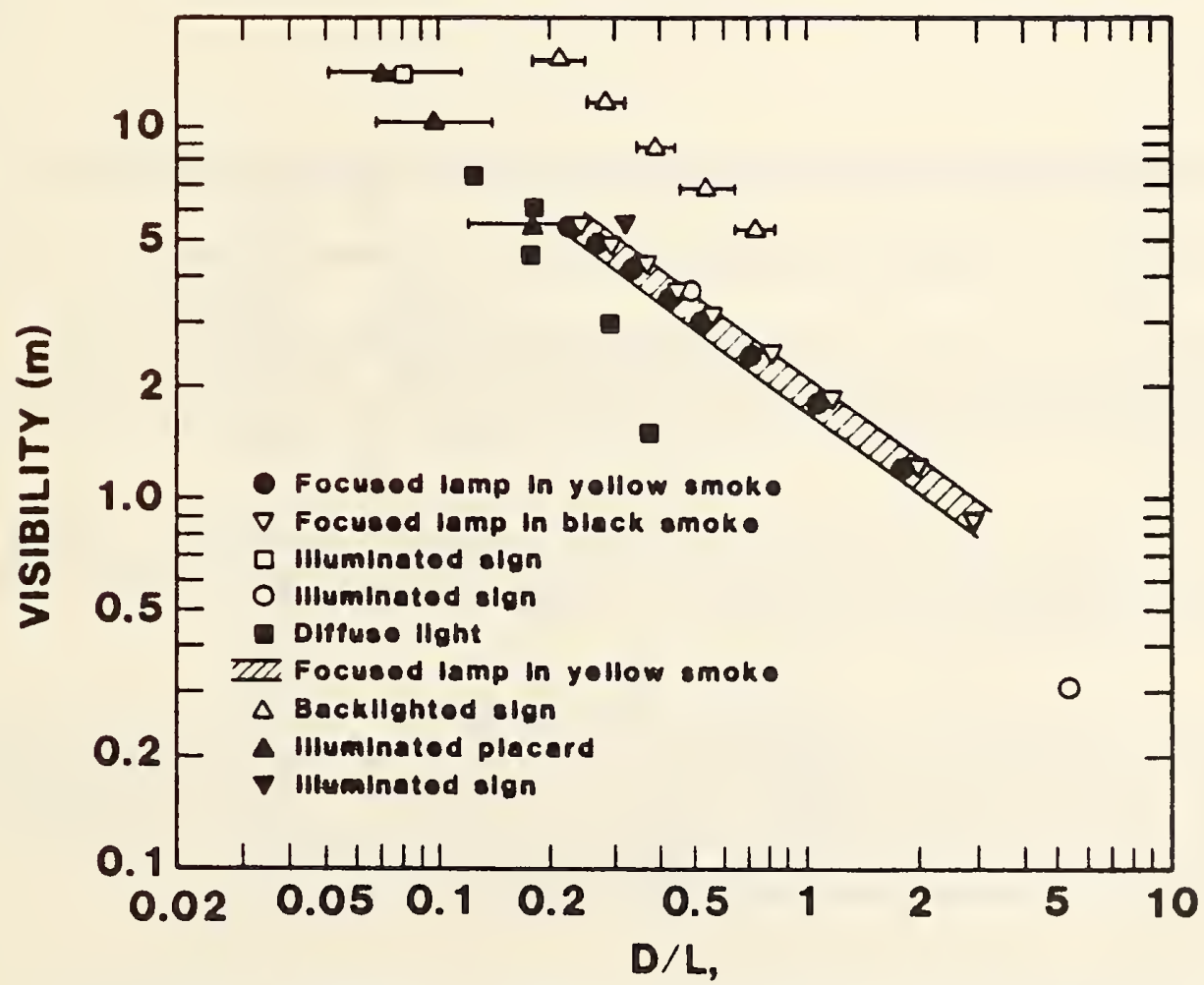

OPTICAL DENSITY PER PATH LENGTH OF SMOKE $\left(m^{-1}\right)$

Figure B17. Visibility results derived from Rasbash [27], Jin [28] and Lopez [29]. 
To compute (D/L) for a closed system, for example a room and adjacent space, the following relationship must be integrated over time:

$$
\frac{d(D / L)}{d t}=\frac{\alpha x_{s}}{V} \dot{m}_{f}
$$

where $t$ is time

$\alpha$ is the particle optical density

and $\quad V$ is the volume of the enclosed space.

The mass loss rate $\dot{m}_{f}$ should be initially estimated from free burn analysis as before. This will be valid in the early stages of the fire. Data on $\alpha$ and $X_{S}$, properties of the burning fuel, are needed for each fuel. Seader and ou [30] suggest $\alpha \approx 3300 \mathrm{~m}^{2} / \mathrm{kg}$ for fuels burning in air, and these results for a wide range of fuels are given by Tewarson [26]. (However Tewarson defines $x_{S}$ and $Y_{S}$ and reports $\sigma$, which is related to $\alpha$, as $\alpha=\sigma /\left(2.303 Y_{S}\right)$.) Also $\alpha x_{S}$ can be estimated from the Smoke Density Chamber Test Method described in ASTM E-662. It can be shown that

$$
\alpha \chi_{S}=\frac{D_{S, \max }}{m^{\prime \prime}}
$$

where $\quad D_{S}$, max is the maximum specific optical density measured in ASTM E-662 and $\mathrm{m}^{\prime}$ is the mass of sample consumed per unit of exposed surface area.

of course the values of $\alpha$ and $\chi_{s}$ for a given material will depend on the exposure conditions during the burning of those samples. For first order estimates these effects are ignored, but judgment must be used in the application of such data.

The estimate based on Eq. (51) assumes that the volume of interest is well mixed and here the filling time has been ignored. Table B 3 gives some representative values for $\alpha$ and $x_{s}$.

An important point that should be noted in the discussion above is that in ventilation limited conditions, $\dot{m}_{f}$ depends on air $f l$ ow and $\chi_{s}$ has been shown to increase. The ventilation parameter $A_{O} \sqrt{\mathrm{H}_{\mathrm{O}}}$ is reduced. This is shown in Figure B18 from the work of Saito [31] for plywood burning in an enclosure of floor area A. 
Smoke properties for selected materials burning in air [26]

$$
\begin{gathered}
\text { Particle Optical } \\
\text { Density }
\end{gathered}
$$

Material

Oak

PILA

Polyurethane foam

flexible (GM-25)

Granular Polystyrene

\subsection{1}

$\left(10^{3} \mathrm{~m}^{2} / \mathrm{kg}\right)$

3.17

4.65

0.426

0.32
Fraction of Particulate Mass to Fuel Mass Loss

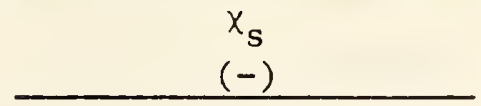

0.013

0.021

0.15

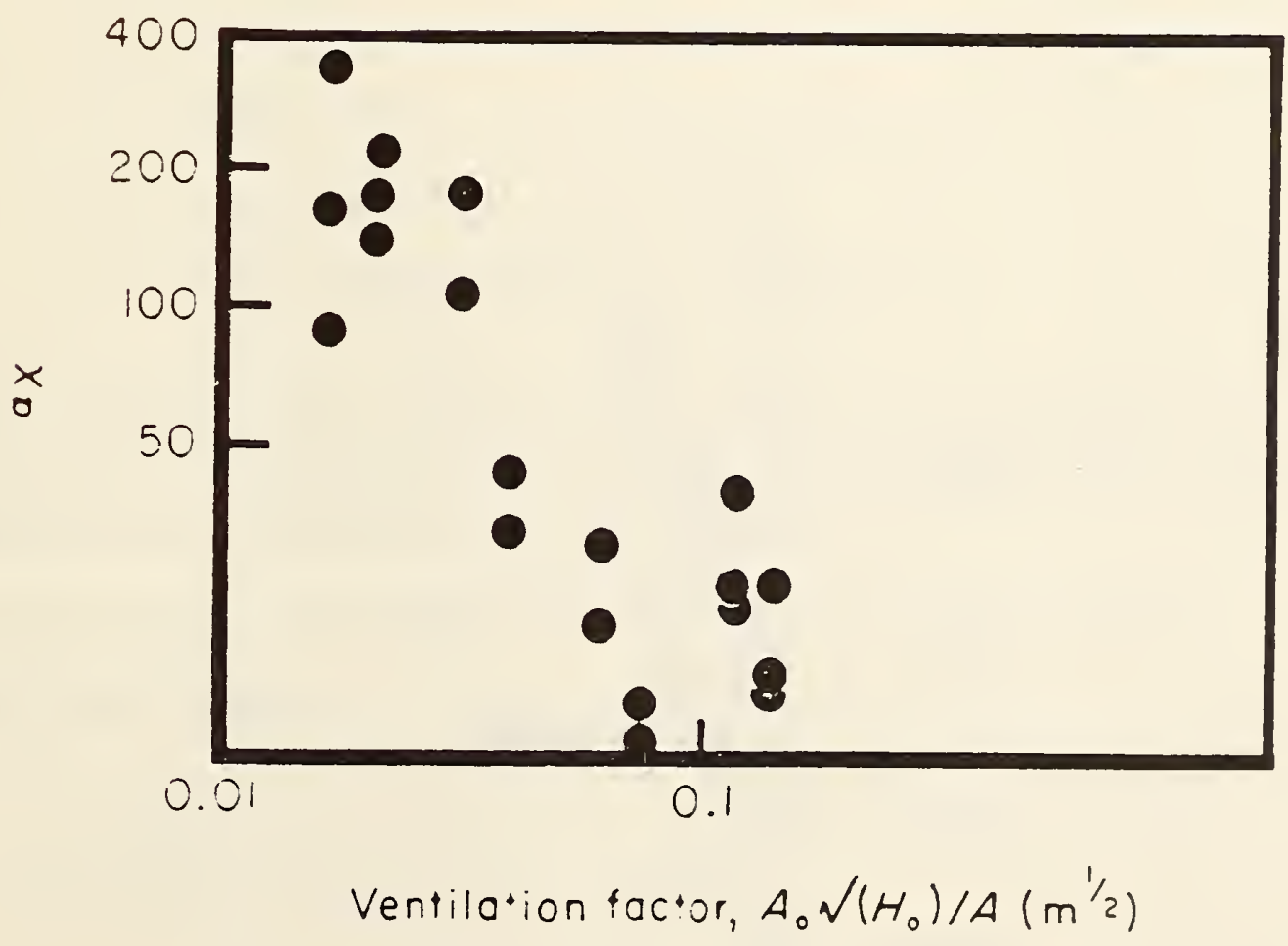

Figure B18. Smoke production for plywood as a function of ventilation factor from Saito [31] 


\section{Estimation of Flame Spread Rates}

After an unwanted fire has started flames spread away from the point of origin. The rate of flame spread, $V_{f}$, is affected by several environmental factors and the thermophysical/thermochemical properties of the materials. For solids of thickness $>1 \mathrm{~mm}$ Eq. (53) Quintiere and Harkleroad [32] illustrate some of these variables.

$\underline{\text { Solids }}$

$$
V_{f} \propto \frac{\left(T_{f}-T_{i g}\right)^{2}}{k_{\rho c}\left(T_{i g}-T_{s}\right)^{2}}
$$

where $\quad \mathrm{T}_{\mathrm{f}}$ - is the flame temperature which depends on available oxygen

$$
\begin{aligned}
& \mathrm{T}_{\text {ig }} \text { - is the ignition temperature } \\
& \mathrm{T}_{\mathrm{S}} \text { - is the upstream surface temperature resulting from an } \\
& \text { external heat flux. }
\end{aligned}
$$

Figure B19 schematically depicts the plume spread phenomena.

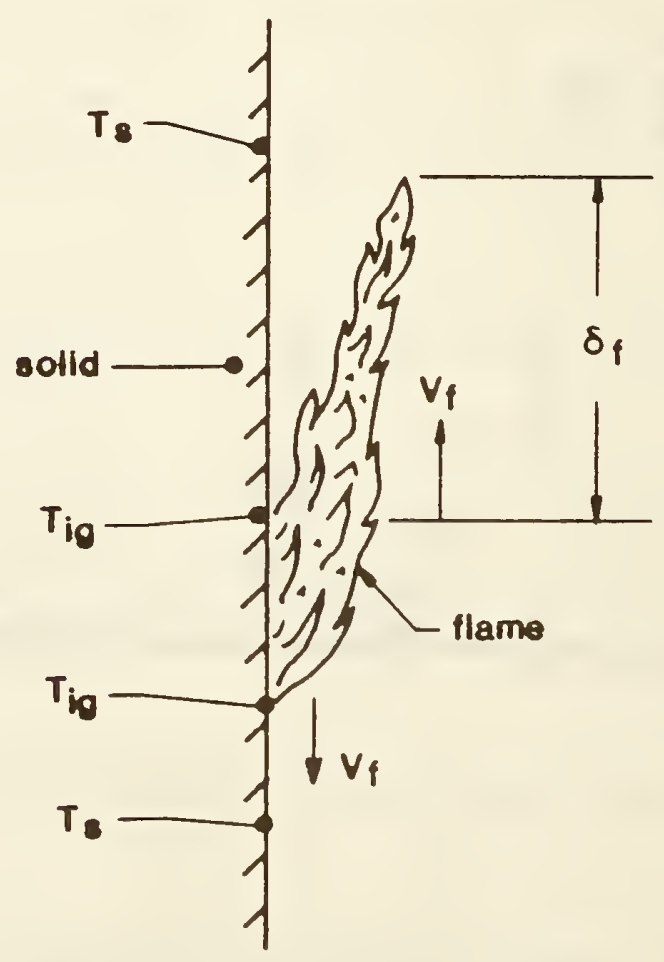

Figure B19. Sketch of flame spread model. 
The relationship shown above can be converted into an estimate of downward flame spread rate using,

\section{Flame Spread Opposed to Flow (downward)}

$$
V_{f} \approx \frac{\phi}{k_{\rho c}\left(T_{i g}-T_{S}\right)^{2}}
$$

where

$$
\Phi=V_{a}(k \rho c)_{g}\left(T_{E}-T_{i g}\right)^{2}
$$

and

$$
V_{a}=\frac{\left(\frac{k}{\rho c}\right) g\left(T_{f}-T_{\infty}\right) 1 / 3}{T_{\infty}}
$$

where $k_{\mathrm{g}}=$ thermal conductivity of gas phase

$$
\rho_{g}=\text { specific heat of gas }
$$$$
c_{g}=\text { specific heat of gas }
$$$$
\mathrm{g}=\text { gravitational acceleration }\left(9.8 \mathrm{~m} / \mathrm{s}^{2}\right)
$$

$\mathrm{T}_{\mathrm{f}}=$ adiabatic flame temperature

$\mathrm{T}_{\infty}=$ ambient and initial temperature

It has been found for a wide range of materials that $\Phi$ generally ranges between 1 and $15(\mathrm{~kW})^{2} / \mathrm{m}^{3} ; \mathrm{T}_{i}$, ranges between 250 and $600^{\circ} \mathrm{C}$; and $\mathrm{k} \rho \mathrm{c}$ ranges between 0.01 and $1.0\left(\mathrm{~kW} / \mathrm{m}^{2} \mathrm{~K}\right)^{2} \mathrm{~s}[32]$. These are to be considered pseudo-properties valid for Eq. (54) under opposed flow natural convection flame spread in vertical orientation.

For upward flame travel, flame spread rate can be described by:

\section{Upward Flame Spread}

$$
V_{f} \approx \frac{\left(\dot{q}{ }_{f}\right)^{2} \delta_{f}}{k \rho c\left(T_{i g}-T_{s}\right)^{2}}
$$

where $q "{ }_{\mathrm{f}}=$ heat transfer per unit time and per unit area

and

$$
\delta_{\mathrm{f}}=\mathrm{flame} \text { extension length }
$$

Practical applications of Eq. (57) have not been developed, and general methods for predicting $\dot{q}_{\mathrm{f}}$ and $\delta_{\mathrm{f}}$ do not exist. 


\section{Flame Spread Over Liquids}

Glassman [33] reports on recent research efforts and theories for flame spread over liquids. As is shown in Figure B20, there are basically two different regimes for fires on liquids. One regime relates to flame spread which is controlled by gas phase phenomena when the bulk liquid cemperature $\left(\mathrm{T}_{\mathrm{L}}\right)$ reaches its flash point or, for sustained burning, its fire point temperature $\mathrm{T}_{\mathrm{f}}$. The other regime occurs when the bulk liquid temperature is below its fire point temperature. This slower flame spread phenomena depends on the evaporation of the liquid to sustain and control the process. As the liquid temperature rises above the fire point temperature to $\mathrm{T}_{\mathrm{LSt}}$, a stoichiometric fuel-air mixture is formed near the surface, and consequently flame spread occurs in the gas phase. This rate of flame spread is related to the bulk liquid temperature and its surface tension.

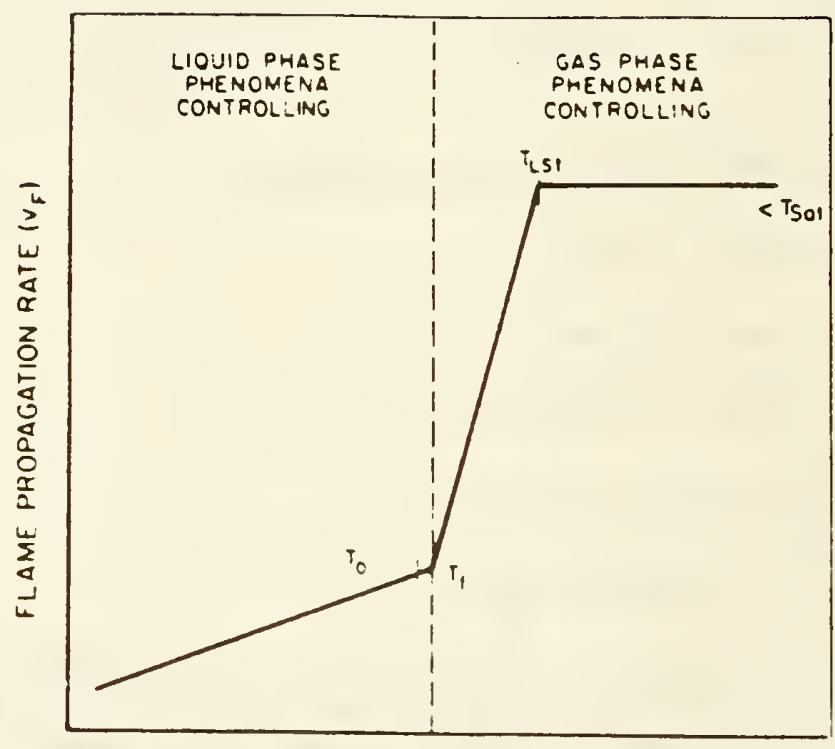

LIQUIO FUEL TEMPERATURE $\left(T_{L}\right)$

Figure B20. Schematic of the flame spreading rate as a function of the liquid temperature of the fuel [33].

A report by Williams [34] gives a qualitative formula for the flame spread rate, $V_{\mathrm{f}}$, on liquid fuels.

$$
V_{f}=\frac{\sigma^{\prime}}{\mu_{\ell}}{\frac{\mu_{\ell}^{2}}{\rho_{\ell} \sigma^{\prime}}}^{1 / 3}
$$

where $\quad \sigma^{\prime}=$ gradiant in surface tension

$$
\sigma^{\prime}=\frac{d \sigma}{d T}\left(T_{1 g}-T_{0}\right) / \ell
$$




$$
\begin{aligned}
& \mathrm{T}_{i g}=\text { liquid ignition temperature } \\
& \mathrm{T}_{0}=\text { initial liquid temperature } \\
& \ell=\text { length characteristic forward flame heat transfer to the liquid } \\
& {u_{\ell}}=\text { liquid viscosity } \\
& \rho_{\ell}=\text { liquid density }
\end{aligned}
$$

The application of this equation to practical problem solving is not straightforward since $\ell$ depends on the heat transfer characteristics of the particular problem. Referral to references [33,34] will give some further background and insight on potential applications.

\section{Fully Developed Fire Burn Time}

Once a fire has started and has become fully developed, it is of interest to be able to estimate the duration of burning. This can be easily estimated by

or

$$
t_{b} \approx \frac{m_{f}}{\dot{m}_{f}}
$$

$$
\mathbb{m}_{f}=\int_{0}^{t} b \dot{m}_{f} d t
$$

where $m_{f}$ is the mass of fuel available to burn (vaporize) and $\dot{m}_{f}$ is the burning (vaporization) rate of the fuel under the specified environmental conditions. The value for $\dot{\mathrm{m}}_{\mathrm{f}}$ can be estimated using the equations located in section 2.

\section{Conclusion}

To conclude this paper, it would be appropriate to use the techniques presented to make estimates for the development of a hypothetical fire. An exercise of this type is presented in the "Example" which follows section 18.

This report has brought together a number of techniques developed by various researchers for evaluating the fire environment. These predictive methods can be useful in estimating many of the critical elements related to fire behavior and help provide a better understanding of this complex phenomenon. It should be remembered when using this report while making predictions that the results are only estimates. These estimates, which spring from the state-of-the-art, are meant to provide a reasonable approximation and in some cases just an order of magnitude for the particular elements under study. More accurate predictions typically involve more complex calculations using more powerful methods than a simple calculation. In many cases, additional research is needed to formulate new solutions, derive more data, and to develop more sophisticated fire models than currently exist. Nevertheless the approach presented here provides, in addition to its estimates, a conceptual framework for what we can do and what we must learn to do. 
1. Delichatsios, M.A., Fire Growth Rates in Wood Cribs, Combustion and Flame, 27, 267-278 (1976).

2. Heskestad, G., Modeling of Enclosure Fires, 14th Symposium (International) on Combustion, The Combustion Institute, Pittsburgh, p. 1021, (1973).

3. Lawson, J.R., Walton, W.D., Twilley, W.H., Fire Performance of Furnishings as Measured in the NBS Furniture Calorimeter. Part I, National Bureau of Standards (U.S.) NBSIR 83-2787 (1983).

4. Babrauskas, V., Combustion of Mattresses Exposed to Flaming Ignition Sources - Part I. Full Scale Tests and Hazard Analysis, National Bureau of Standards, (U.S.), NBSIR 77-1290, (1977).

5. Orloff, L., Fire Growth on Polyurethane Foam, Modak, A.T., ed., Influence of Enclosures on Fire Growth, Volume II - Analysis, Tech. Report, FMRC J.I. OAOR3.BU, RC78-BT-24, Factory Mutual Research Corp•, Norwood, MA (July 1978).

6. Modak, A.T., Croce, P.A., Plastic Pool Fires, Combustion and Flame, 30, 251-265, (1977).

7. Burgess, D.S., Grumer, J., Wolfhard, H.G., Burning Rates of Liquid Fuels in Large and Small Open Trays, International Symposium on the Use of Models in Fire Research, Publication 786 National Academy of Sciences, (November 1959).

8. Modak, A.T., Thermal Radiation from Pool Fires, Combustion and Flame, 29, 177-192 (1977).

9. McCaffrey, B.J., Purely Buoyant Diffusion Flames: Some Experimental Results, National Bureau of Standards, (U.S.) NBSIR 79-1910 (1979).

10. Zukoski, E. E., Kubota, T., Cetegen, B., Entrainment in Fire Plumes, Fire Safety Journa 1, 3, 107-121 (1980/81).

11. Hasemi, Y., Tokunaga, T., Modeling of Turbulent Diffusion Flames and Fire Plumes for the Analysis of Fire Growth, Fire Dynamics and Heat Transfer, The American Society of Mechanical Engineers, 21 st National Heat Transfer Conference, HTD-Vol. 25, (1983).

12. You, H.Z., Faeth, G.M., Ceiling Heat Transfer During Fire Plume and Flame Impingement, Fire and Materials, Vol 3, (1979).

13. Zukoski, E.E., Development of a Stratified Ceiling Layer in the Early Stages of a Closed-Room Fire, Fire and Materials, Vol. 2, No. 2, (1978).

14. Quintiere, J.G., Birky, M., McDonald, F., Smith, G., An Analysis of Smoldering Fires in Closed Compartments and Their Hazard Due to Carbon Monoxide, Fire and Materials, Vol. 6, Nos. 3 and 4, (1982). 
15. Quintlere, J.G., A Simple Correlation for Predicting Temperature in a Room Fire, National Bureau of Standards (U.S.), NBSIR 83-2712, (1983).

16. McCaffrey, B.J., Quintiere, J.G., Harkelroad, M.F., Estimating Room Temperatures and the Likelihood of Flashover Using Fire Test Data Correlations, Fire Technology, 17, 2, p. 98, (May 1981).

17. Steckler, K.D., Quintiere, J.G., Rinkinen, W.J., Flow Induced by Fire in a Compartment, Nineteenth Symposium (International) on Combustion, The Combustion Institute, pp. 913-920, (1982).

18. Quintiere, J.G., Steckler, K., Corley, D., An Assessment of Fire Induced Flows in Compartments, Fire Science and Technology, Vo1. 4, No. 1, p. 1-14, (June 1984).

19. Kawagoe, K., Sekine, T., Estimation of Fire Temperature - Time Curve for Rooms, Ministry of Construction, Japanese Government, (June 1963).

20. Thomas, P.H., Bullen, M.L., Quintiere, J.G. and McCaffrey, B.J., Flashover and Instabilities in Fire Behavior, Combustion and Flame, 38 , 159-171, (1980).

21. Thomas, P.H., Heselden, A.J.M., Law, M., Fully-Developed Compartment Fires -- Two Kinds of Behavior, Ministry of Technology and Fire Offices Committee, Fire Research Station, Borehamwood, England Technical Paper No. 18, (1967).

22. Zukoski, E.E., Kubota, T., Experimental Study of Environment and Heat Transfer In a Room Fire, Final Report, Grant NB82NADA3033, National Bureau of Standards, (U.S.), (July 1984).

23. Jones, W.W., Quintiere, J.G., Prediction of Corridor Smoke Filling by Zone Models, Combustion Science and Technology, Vol. 35, pp. 239-253, (1984).

24. Quintiere, J.G., Smoke Measurements: An Assessment of Correlations Between Laboratory and Full-Scale Experiments, Fire and Materials, Vol. 6, Nos. 3 and 4, (1982).

25. Babrauskas, V., Applications of Predictive Smoke Measurements, Journal of Fire and Flammability, Vol. 12, p. 51, (January 1981).

26. Tewarson, A., Physico-Chemical and Combustion/Pyrolysis Properties of Polymeric Materials, National Bureau of Standards (U.S.), NBS-GCR-80-295, (1980).

27. Rasbash, D.J., Smoke and Toxic Products Produced at Fires, Plastics Institute Transaction and Journal, pp. 55-61, (January 1967).

28. Jin, T., Visibility through Fire Smoke (Part 2), Report of the Fire Research Institute of Japan, Nos. 33, 31, (1971).

29. Lopez, E.L., Smoke Emission from Burning Cabin Materials and the Effect on Visibility in Wide-Bodied Jet Transports, Journal of Fire and Flammability, Vol. 6, (October 1975). 
30. Seader, J.D., Ou, S.S., Correlation of the Smoking Tendency of Materials, Fire Research, 1, 3-9, (1977).

31. Saito, F., Smoke Generation from Building Materials, 15th Symposium (International) on Combustion, The Combustion Institute, 269 (1974).

32. Quintiere, J.G., Harkelroad, M., New Concepts for Measuring Flame Spread Properties, presented at Symposium on Application of Fire Science to Fire Engineering, ASTM, SFPE, (June 1984).

33. Glassman, I., Dryer, F.L., Flame Spreading Across Liquid Fuels, Fire Safety Journal, Vol. 3, Nos. 2-4, (January-March 1981).

34. Williams, F.A., Mechanisms of Fire Spread, Sixteenth Symposium (International) on Combustion, The Combustion Institute, 1281-1294, (1976). 
This exercise is designed to provide an example of the use of the predictive methods presented in this report. It is intended as a hypothetical illustration and should not be construed as representative of the hazard associated with the particular items, materials and occupancy configuration selected. The first step in analyzing a fire scenario is to define the problem in terms of information required by the relevant predictive formulae.

\title{
Problem:
}

The fire takes place in a hotel room. A fire starts from a cigarette lighter in the center of a bed with a polyurethane foam mattress. The room door is left $1 / 4$ open as the occupant flees the room. Figure B21 shows the plan for the hotel section being studied.

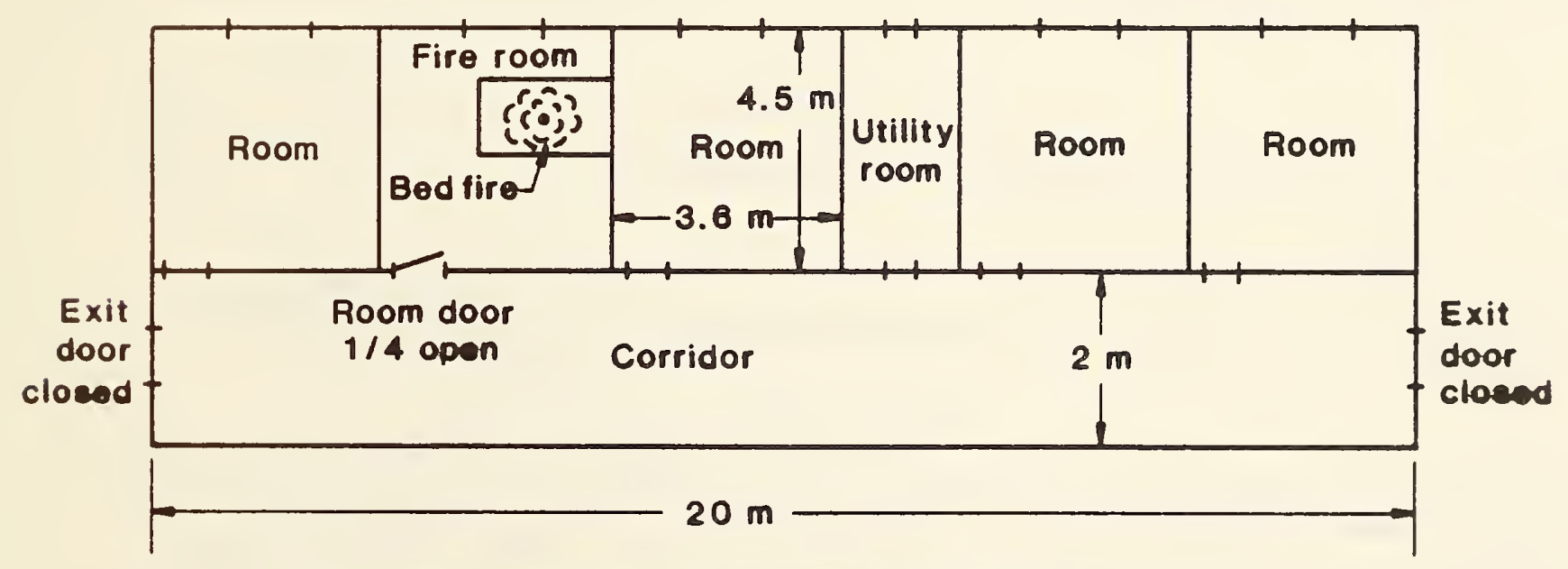

\section{Note: Coiling height in rooms and corridors $2.4 \mathrm{~m}$. All doors are closed except the fire door.}

\author{
Figure El. Room Fire Example
}

\section{Analysis of Fire Growth and Consequences}

In this section, the prediction methods presented earlier are used to calculate mass loss rate, heat release rate, flame height, ceiling heat flux, temperature rise, ventilation flow rate, visibility, smoke filling, and smoke transport for the sample problem. The data required to make these calculations are provided as well as the assumptions used to simplify the calculation process. Tables of predicted values are presented and selected results are shown graphically.

\section{Mass Loss Rate}

The first step in these predictions of fire growth and hazardous conditions is the determination of an expression for energy generation rate of the fire. Using Eq. (3) with $\beta=0$ yields the following expression for fuel mass loss rate. 


$$
\dot{m}=\alpha e^{\alpha t} \text { where } \alpha=0.03
$$

The solution to this expression is shown in Table El and Figure E2 for times up to $250 \mathrm{~s}$. Mass loss rates for times from $250 \mathrm{~s}$ to $300 \mathrm{~s}$ are calculated using the steady state burning formula for wood cribs:

$$
\dot{\mathrm{m}}_{\mathrm{f}}=0.09 \mathrm{w}_{\mathrm{o}} \mathrm{H}_{\mathrm{o}}^{3 / 2}
$$

where $W_{0}=0.23$

$$
\mathrm{H}_{\mathrm{O}}=2
$$

This represents the ventilation-limited fire case. It is employed at the time when the ratio of fuel mass loss rate to air flow rate to the room exceeds its stoichiometric ratio (8).

\section{Heat Release Rate}

Heat release rate was calculated using the equation:

$$
\dot{Q}=\dot{\mathrm{m}} \Delta \mathrm{H}
$$

where $\Delta \mathrm{H}=15.7(\mathrm{~kJ} / \mathrm{g})$ for the polyurethane foam matress in the example.

\section{Radiant Flux}

From the heat release rate the radiant heat transfer to a nearby surface can be calculated using Eq. (7). In this prediction, it is assumed that $\mathrm{R}_{0}$, the distance from the heat source to the wall is $1.8 \mathrm{~m}$. The $\mathrm{xr}_{\mathrm{r}}$ value for polyurethane foam in this example is 0.35 . Both values for $\dot{Q}$ and $\dot{q}_{o}{ }^{\prime}\left(R_{o}\right)$ are presented in Table El The radiant flux $\dot{q}_{0}^{\prime \prime}\left(R_{0}\right)$ as a function of time is shown in Figure E3.

\section{Flame Height}

The values for flame height, $H_{f}$, and ceiling flame impingement length, $H_{R}$, in Table El and Figure E4 were calculated using Eqs. (8) and (14), respectively. In Eq. (14), the value for $\mathrm{H}=1.8 \mathrm{~m}$ since the bed height is subtracted from the overall ceiling height, and $D$ was selected as a constant of $0.5 \mathrm{~m}$. (Although the fire is growing, it is not strongly dependent on D.)

\section{Ceiling Heat Flux}

Table E1 and Figure E3 also contain predictions for heat flux to the room's ceiling. These results were developed using Eq. (15b). The values for radiant flux derived from Eq. (7) were added to values from Eq. (15b) to predict the total heat flux to the celling. In this example radiation from the hot gas layer has not been included in the total heat flux to the ceiling. However, an upper limit for radiation to the ceiling from the hot gas layer can be estimated as $\sigma \mathrm{T}^{4}$ where $\sigma$ is $5.6697 \times 10^{-8} \mathrm{~W} / \mathrm{m}^{2}-\mathrm{K}^{4}$. 
Predictions for gas temperature rise, $\Delta T$, in the room are presented in column 8 of Table EL. Also see Figure E5. These values were generated using Eq. (31), but before the various temperatures were calculated thermal penetration times, $t_{p}$, for the gypsum walls and plywood floors were determined. The following parameters were used in these calculations:

Gypsum wallboard (walls/ceiling)

$$
\begin{aligned}
t_{p} & =393 \mathrm{~s} \\
\rho & =960 \mathrm{~kg} / \mathrm{m}^{3} \\
c & =1.1 \mathrm{~kJ} /(\mathrm{kg}-\mathrm{K}) \\
\mathrm{k} & =1.7 \times 10^{-4} \mathrm{~kJ} /(\mathrm{m}-\mathrm{K}) \\
\delta & =0.0159 \mathrm{~m}
\end{aligned}
$$

Plywood (floor)

$$
\begin{aligned}
t_{p} & =711 \mathrm{~s} \\
\rho & =540 \mathrm{~kg} / \mathrm{m}^{3} \\
c & =2.5 \mathrm{~kJ} /(\mathrm{kg}-\mathrm{K}) \\
\mathrm{k} & =1.2 \times 10^{-4} \mathrm{~kJ} /(\mathrm{m}-\mathrm{K}) \\
\delta & =0.0159 \mathrm{~m}
\end{aligned}
$$

As a result of these calculations, it was found that values for $h_{k}$ in Eq. (31) would be determined using $\sqrt{\mathrm{kpc} / \mathrm{t}}$ where $t \leq t_{p}$. At this point, it is important to note that new values for $h_{k}$ are calculated with each new time in the prediction of $\Delta T$. For $t \leq t_{p}, h_{k}$ was calculated by

$$
h_{k}=\frac{A_{1} h_{k, 1}+A_{2} h_{k, 2}}{A}
$$

where

$$
\begin{aligned}
& A_{1}=55.08 \mathrm{~m}^{2} \text { area for walls and ceilings } \\
& A_{2}=16.2 \mathrm{~m}^{2} \text { area for floor } \\
& A=71.28 \mathrm{~m}^{2} \text { total }
\end{aligned}
$$

and $h_{k, 1}$ and $h_{k, 2}$ correspond to the gypsum board and plywood respectively. When extended calculations are made for $t>t$ for either the walls and ceiling or floor, $\mathrm{k} / \delta$ should be substituted into the above equation. For 
$\Delta T$ calculations at times greater than the point of flashover, Eq. (41) was used. Values for the parameter in Eq. ( 31 and 41 ) are as follows:

$$
\begin{aligned}
& \mathrm{g}=9.8 \mathrm{~m} / \mathrm{s}^{2} \\
& \mathrm{c}_{\mathrm{p}}=1.046 \mathrm{~kJ} /(\mathrm{kg}-\mathrm{K}) \\
& \mathrm{\rho}_{\mathrm{o}}=1.25 \mathrm{~kg} / \mathrm{m}^{3} \\
& \mathrm{~T}_{\mathrm{o}}=293 \mathrm{~K} \\
& \mathrm{~A}_{\mathrm{o}}=0.46 \mathrm{~m}^{2} \\
& \mathrm{H}_{\mathrm{o}}=2 \mathrm{~m}
\end{aligned}
$$

\section{Ventilation Flow Rate}

Since both $\dot{Q}$ and $\Delta T$ are now available, ventilation flow rate is calculated. In this procedure, Eqs. $(32,33,34$ and 35$)$ are used to make the predictions. For times down to $220 \mathrm{~s}$ where $\psi \leq 1$, y $2=0.5$ was used in the calculation. For $\psi>1$, Eq. (33) was used to calculate an estimated value of $y_{2}$. This was done by substituting the preceeding result of $\dot{m}_{i}$ into the equation. The values of $\mathrm{M}_{0}$ and $\dot{\mathrm{m}}_{0}$ were determined using Eqs. ( 32 and 34 ), and $\dot{\mathrm{m}}_{i}$ results were found with Eq. (35). The values used in this calculation were as follows:

$$
\begin{aligned}
\rho_{\mathrm{a}} & =1.25 \mathrm{~kg} / \mathrm{m}^{3} \\
\mathrm{~g} & =9.8 \mathrm{~m} / \mathrm{s}^{2} \\
\mathrm{~W}_{\mathrm{o}} & =0.23 \mathrm{~m} \\
\mathrm{H}_{\mathrm{O}} & =2 \mathrm{~m}
\end{aligned}
$$

It can be seen in Table El and Figure E6 that the ventilation starts to drop off at about $220 \mathrm{~s}$ and then starts to rise again. The $220 \mathrm{~s}$ point is where the estimated value for $\mathrm{y}_{2}$ was started, and it is continued until the ventilation limit condition is reached at a time between 250 and $255 \mathrm{~s}$. At this point and beyond, the $\dot{m}_{f}$ value is based on steady state enclosure ventilation limited formula, and the calculation for $\dot{m}_{i}$ was stopped.

\section{Corridor Visibility}

The last column in Table El consists of predictions of visibility, $\mathrm{L}_{\mathrm{v}}$, in the corridor. Also see Figure E7. The equation used in this prediction was as follows :

$$
L_{v}=\frac{k v}{\alpha x} \quad \int_{0}^{t} \text { in } d t
$$


where

$$
\begin{aligned}
k_{v}= & 2 \\
V & =(\text { Width })(\text { length) (height) of corridor } \\
& (2 \mathrm{~m}) \quad(20 \mathrm{~m})(2.4 \mathrm{~m})
\end{aligned}
$$

and

$$
\begin{aligned}
& \int_{0}^{t} \dot{m} d t=\int_{0}^{t} \alpha e^{\alpha t} d t=e^{\alpha t}-\left.1\right|_{0} ^{t} \text { for mattress } \\
& \alpha=3300 \mathrm{~m}^{2} / \mathrm{kg} \\
& x=0.3 \mathrm{~g} \text { smoke particulates } / \mathrm{g} \text { fuel }
\end{aligned}
$$

These predictions show that visibility would be about 0.1 w when flashover (based on $\Delta T=500^{\circ} \mathrm{C}$ ) occurs. (It should be noted that this calculation assumes a well-mixed gas state in the corridor. But this does not occur until 181s approximately. So use of the formulae before this time will over estimate the visibility by the ratio of corridor volume to actual smoke layer volume.

\section{Smoke Filling}

Two other tables are presented in this example. Table E2 is a listing of various room smoke filling times based on different steady state heat release rates. Equation ( $23 \mathrm{~b}$ ) was usd to calculate these values. The following values were used in these calculations:

$$
\begin{aligned}
\alpha & =1 / 5.4 \\
\rho_{\infty} & =1.25 \mathrm{~kg} / \mathrm{m}^{3} \\
T_{\infty} & =293 \mathrm{~K} \\
c_{p} & =1.046 \mathrm{~kJ} / \mathrm{kg}-\mathrm{k} \\
g & =9.8 \mathrm{~m} / \mathrm{s}^{2} \\
H & =2.4 \mathrm{~m} \\
s & =16.2 \mathrm{~m}^{2}
\end{aligned}
$$

These results suggest that combustion products begin to leave the room 1.e., the layer is just below the door soffit $(H=1.99 \mathrm{~m})$ at about 10 to $35 \mathrm{~s}$.

Table E3 contains additional predictions which provides an order of events for the fire growth example. Smoke filling time for the room was taken from Table $E 2$, and visibility in the corridor was taken from Table El. The value for smoke filling time in the corridor was generated using Eqs. (45, 46, and 48). Parameter values used in this calculation were as follows: 


$$
\begin{aligned}
\rho_{a} & =1.24 \mathrm{~kg} / \mathrm{m}^{3} \\
\mathrm{~g} & =9.8 \mathrm{~m} / \mathrm{s}^{2} \\
\mathrm{H}_{\mathrm{c}} & =2.32 \mathrm{~m} \\
\dot{Q} & =100 \mathrm{~kW} \\
\mathrm{~L}_{\mathrm{c}} & =1.046 \mathrm{~kJ} / \mathrm{kg}-\mathrm{K} \\
\mathrm{T}_{\mathrm{a}} & =293 \mathrm{~K} \\
\tau & =47 \\
\mathrm{~A} & =40 \mathrm{~m}^{2}
\end{aligned}
$$

The time for the occurrence of flashover and the ventilation limit time was taken from Table El. The time for flashover is based on a $500^{\circ} \mathrm{C}$ temperature rise, and the ventilation limit is based on the effective fuel-air mass ratio where

$$
\gamma=\frac{\Delta \mathrm{H}_{\text {air }}}{\Delta \mathrm{H}_{\text {fuel }}}=\frac{3.03 \mathrm{~kJ} / \mathrm{g} \text { air }}{15.7 \mathrm{~kJ} / \mathrm{g} \text { fuel }}=0.193 \mathrm{~g} \text { fuel } / \mathrm{g} \text { air }
$$

This mass ratio was compared with fuel and air values contained in Table El. Smoke Transport

The predictions at the bottom of Table E3 were developed using Eq. (42) where

$$
\begin{aligned}
& \rho_{c} \text { was selected to correspond to the room temperature }(T) \text { so that } \\
& \frac{\rho_{a}-\rho_{c}}{\rho_{a}}=1-\frac{T a}{T} \text {. }
\end{aligned}
$$

Parameters used in this calculation were as follows:

$$
\begin{aligned}
\mathrm{g} & =9.8 \mathrm{~m} / \mathrm{s}^{2} \\
\mathrm{~T}_{\mathrm{a}} & =293 \mathrm{~K} \\
\mathrm{~T} & =303 \mathrm{~K} \\
\mathrm{H} & =2.4 \mathrm{~m}
\end{aligned}
$$

Smoke transport times to the corridor ends were calculated using Eq. (43). Center line distances from the hotel room door were $4.2 \mathrm{~m}$ and $15.8 \mathrm{~m} \mathrm{respec-}$ tively for the near and far ends of the corridor. 
Thus a chronology of significant events and the magnitude of physical fire effects have been estimated for this scenario. It's accuracy is at least good to an order of magnitude and more exact assessments of accuracy mist be based on the assumptions and support literature for each of the formulas used. 
Table El. Fire Growti Predictions

\begin{tabular}{|c|c|c|c|c|c|c|c|c|c|}
\hline $\begin{array}{c}e \\
(E) \\
\end{array}$ & 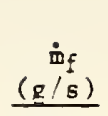 & $\begin{array}{c}Q \\
\left(k k^{\prime}\right) \\
\end{array}$ & $\begin{array}{l}\dot{q}_{0}^{*}\left(R_{0}\right) \\
\left(k H / \mathbb{a}^{2}\right) \\
\end{array}$ & $\begin{array}{l}H_{f} \\
\text { (II) } \\
\end{array}$ & $\begin{array}{l}\mathrm{R}_{\mathrm{R}} \\
(\mathrm{E}) \\
\end{array}$ & $\begin{array}{l}\dot{q}^{*}(0) \\
\left(k \omega / \mathbf{m}^{2}\right) \\
\end{array}$ & $\begin{array}{l}\Delta \mathrm{T} \\
\left({ }^{\circ} \mathrm{C}\right) \\
\end{array}$ & $\begin{array}{c}\dot{\dot{v}}_{1} \\
(\mathrm{~kg} / \mathrm{s}) \\
\end{array}$ & $\begin{array}{c}\text { Corridor } \\
\mathrm{L}_{\mathrm{v}} \\
(\mathrm{v}) \\
\end{array}$ \\
\hline 0 & 0.00 & 0.0 & - & - & - & - & - & - & - \\
\hline 10 & 0.04 & 0.6 & - & - & - & - & - & - & - \\
\hline 20 & 0.05 & 0.8 & - & - & - & - & - & - & - \\
\hline 30 & 0.07 & 1.1 & - & - & - & - & - & - & - \\
\hline 40 & 0.10 & 1.6 & - & 0.28 & - & 0.11 & 1 & 0.034 & 83.6 \\
\hline 45 & 0.12 & 1.9 & - & 0.29 & - & 0.12 & 7 & 0.090 & 67.9 \\
\hline 50 & 0.13 & 2.0 & - & 0.30 & - & 0.13 & 8 & 0.095 & 55.7 \\
\hline 55 & 0.16 & 2.5 & - & 0.33 & - & 0.15 & 9 & 0.101 & 46.1 \\
\hline 60 & 0.18 & 2.8 & - & 0.35 & - & 0.17 & 10 & 0.106 & 38.4 \\
\hline 65 & 0.21 & 3.3 & - & 0.37 & - & 0.19 & 11 & 0.111 & 32.1 \\
\hline 70 & 0.24 & 3.8 & - & 0.39 & - & 0.22 & 12 & 0.115 & 27.1 \\
\hline 75 & 0.28 & 4.4 & - & 0.42 & - & 0.24 & 14 & 0.124 & 22.8 \\
\hline 80 & 0.33 & 5.2 & - & 0.44 & - & 0.28 & 15 & 0.128 & 19.3 \\
\hline 85 & 0.38 & 6.0 & - & 0.47 & - & 0.32 & 17 & 0.135 & 16.4 \\
\hline 90 & 0.45 & 7.1 & - & 0.50 & - & 0.36 & 19 & 0.142 & 14.0 \\
\hline 95 & 0.52 & 8.2 & - & 0.53 & - & 0.41 & 21 & 0.149 & 11.9 \\
\hline 100 & 0.60 & 9.4 & - & 0.56 & - & 0.46 & 24 & 0.157 & 10.2 \\
\hline 105 & 0.70 & 11.0 & 0.09 & 0.60 & - & 0.52 & 27 & 0.164 & 8.7 \\
\hline 110 & 0.81 & 12.7 & 0.11 & 0.64 & - & 0.59 & 29 & 0.169 & 7.4 \\
\hline 115 & 0.94 & 14.8 & 0.13 & 0.68 & - & 0.67 & 33 & 0.178 & 6.4 \\
\hline 120 & 1.10 & 17.3 & 0.15 & 0.72 & - & 0.76 & 37 & 0.186 & 5.4 \\
\hline 125 & 1.28 & 20.1 & 0.17 & 0.76 & - & 0.87 & 41 & 0.194 & 4.7 \\
\hline 130 & 1.48 & 23.2 & 0.20 & 0.81 & - & 0.98 & 45 & 0.200 & 4.0 \\
\hline 135 & 1.72 & 27.0 & 0.23 & 0.86 & - & 1.11 & 50 & 0.208 & 3.4 \\
\hline 140 & 2.00 & 31.4 & 0.27 & 0.91 & - & 1.26 & 56 & 0.216 & 3.0 \\
\hline 145 & 2.32 & 36.4 & 0.31 & 0.97 & - & 1.42 & 62 & 0.223 & 2.5 \\
\hline$: 50$ & 2.70 & 42.4 & 0.36 & 1.03 & - & 1.61 & 69 & 0.231 & 2.2 \\
\hline 155 & 3.14 & 49.3 & 0.42 & 1.09 & - & 1.83 & 77 & 0.238 & 1.9 \\
\hline 160 & 3.65 & 57.3 & 0.49 & 1.16 & - & 2.07 & 86 & 0.245 & 1.6 \\
\hline 165 & 4.24 & 65.5 & 0.57 & 1.23 & - & 2.35 & 95 & 0.251 & 1.4 \\
\hline 170 & 4.92 & 77.2 & 0.66 & 1.31 & - & 2.66 & 106 & 0.257 & 1.2 \\
\hline 175 & 5.72 & 89.8 & 0.77 & 1.39 & - & 3.01 & 117 & 0.263 & 1.0 \\
\hline 180 & 6.64 & 104.2 & 0.90 & 1.48 & - & 3.41 & 130 & 0.267 & 0.9 \\
\hline 185 & 7.72 & 121.2 & 1.04 & 1.57 & - & 3.87 & 145 & 0.272 & 0.8 \\
\hline 190 & 8.97 & 140.8 & 1.21 & 1.66 & - & 4.39 & 161 & 0.275 & 0.7 \\
\hline 195 & 10.42 & 163.6 & 1.41 & 1.77 & - & 4.97 & 178 & 0.278 & 0.6 \\
\hline 200 & 12.10 & 190.0 & 1.63 & 1.88 & 0.07 & 5.63 & 198 & 0.279 & 0.5 \\
\hline 205 & 14.06 & 220.7 & 1.90 & 1.99 & 0.10 & 6.38 & 219 & 0.280 & 0.41 \\
\hline 210 & 16.34 & 256.5 & 2.20 & 2.12 & 0.25 & 7.23 & 243 & 0.279 & 0.36 \\
\hline 215 & 18.98 & 298.0 & 2.56 & 2.25 & 0.34 & 8.19 & 270 & 0.278 & 0.31 \\
\hline 220 & 22.05 & 346.2 & 2.98 & 2.38 & 0.42 & 9.28 & 300 & 0.288 & 0.26 \\
\hline 225 & 25.62 & 402.2 & 3.46 & 2.53 & 0.52 & 10.52 & 332 & 0.293 & 0.23 \\
\hline 230 & 29.77 & 467.4 & 4.02 & 2.69 & 0.62 & 11.92 & 369 & 0.297 & 0.20 \\
\hline 235 & 34.59 & 543.1 & 4.67 & 2.86 & 0.73 & 13.51 & 409 & 0.300 & 0.17 \\
\hline 240 & 40.18 & 630.8 & 5.42 & 3.03 & 0.83 & 15.30 & 453 & 0.301 & 0.14 \\
\hline 245 & 46.69 & 733.0 & 6.31 & 3.22 & 0.94 & 17.34 & 503 & 0.301 & 0.12 \\
\hline 250 & 54.24 & 851.6 & 7.32 & 3.42 & 1.06 & 19.65 & 558 & 0.300 & 0.11 \\
\hline 255 & 58.55 & Steady & stace wood & $c r i b$ bus & & & 630 & & \\
\hline 260 & 58.55 & & & & & & 632 & & \\
\hline 265 & 58.55 & & & & & & 634 & & \\
\hline 270 & 58.55 & & & & & & 636 & & \\
\hline 275 & 58.55 & & & & & & 638 & & \\
\hline 280 & 58.55 & & & & & & 640 & & \\
\hline 285 & 58.55 & & & & & & 642 & & \\
\hline 290 & 58.55 & & & & & & 644 & & \\
\hline 295 & 58.55 & & & & & & 646 & & \\
\hline 300 & 58.55 & & & & & & 648 & & \\
\hline
\end{tabular}


Table E2. Roos Smoke Filling Time

Predictions, Steady State Fires

\begin{tabular}{|c|c|c|c|c|}
\hline $\begin{array}{r}\text { Trae } \\
\text { (s) }\end{array}$ & $\begin{array}{l}\text { Heat Release } \\
\text { Rate } 0.5 \mathrm{~kW} \\
\text { Smoke layer } \\
\text { helght } \\
\text { (II) }\end{array}$ & $\begin{array}{l}\text { Heat Release } \\
\text { Rate I.C kw } \\
\text { Smoke layer } \\
\text { he1ght } \\
\text { (田) }\end{array}$ & $\begin{array}{l}\text { Heat Release } \\
\text { Rate } 10 \mathrm{~kW} \\
\text { Smoke layer } \\
\text { he1ght } \\
\text { (ख) }\end{array}$ & $\begin{array}{l}\text { Heat Release } \\
\text { Rate } 100 \mathrm{~kW} \\
\text { Smoke layer } \\
\text { he1ght } \\
\text { (m) }\end{array}$ \\
\hline 0 & 0.00 & 0.00 & 0.00 & 0.00 \\
\hline 2 & 2.38 & 2.37 & 2.34 & 2.27 \\
\hline 4 & 2.35 & 2.34 & 2.28 & 2.15 \\
\hline 6 & 2.33 & 2.32 & 2.22 & 2.04 \\
\hline 8 & 2.31 & 2.29 & 2.17 & 1.95 \\
\hline 10 & 2.29 & 2.26 & 2.12 & \\
\hline 12 & 2.27 & 2.24 & 2.07 & Note: 1.99 (m) \\
\hline 14 & 2.25 & $2.2 !$ & 2.02 & Reached \\
\hline 16 & 2.23 & 2.19 & 1.97 & (c) $7(6)$ \\
\hline 18 & $2.2 !$ & 2.16 & & \\
\hline 20 & 2.19 & 2.14 & Note: 1.99 (m) & \\
\hline 22 & 2.17 & 2.11 & Reached & \\
\hline 24 & 2.15 & 2.09 & (e) $15(\mathrm{~s})$ & \\
\hline 26 & 2.13 & 2.07 & & \\
\hline 28 & 2.11 & 2.04 & & \\
\hline 30 & 2.09 & 2.32 & & \\
\hline 32 & 2.07 & 2.00 & & \\
\hline 34 & 2.06 & 1.98 & & \\
\hline 36 & 2.04 & & & \\
\hline 38 & 2.02 & Note: $1.09(5)$ & & \\
\hline 40 & 2.00 & Reached & & \\
\hline 42 & 1.99 & e $33(s)$ & & \\
\hline
\end{tabular}

Table E3. Sumary of Critical Event Pred1ctions

Event

Smoke filling of room

Visibility of $1(m)$ in corridor

Sooke fllling of corridor

Occurence of flashover

Ventilation I1m1t in room
Tyme

(s)

$-10-35$

$-175$

$-181$

$-245$

$-250$

Smoke front velocity with $\Delta T$ of $10^{\circ} \mathrm{C}$

Smoke transport time to near end of corridor

Smoke transport time to far end of corridor

$-35.9$
Veloc1ty

( $\mathrm{m} / \mathrm{s}$ )

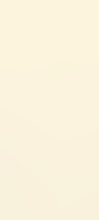

0.44 


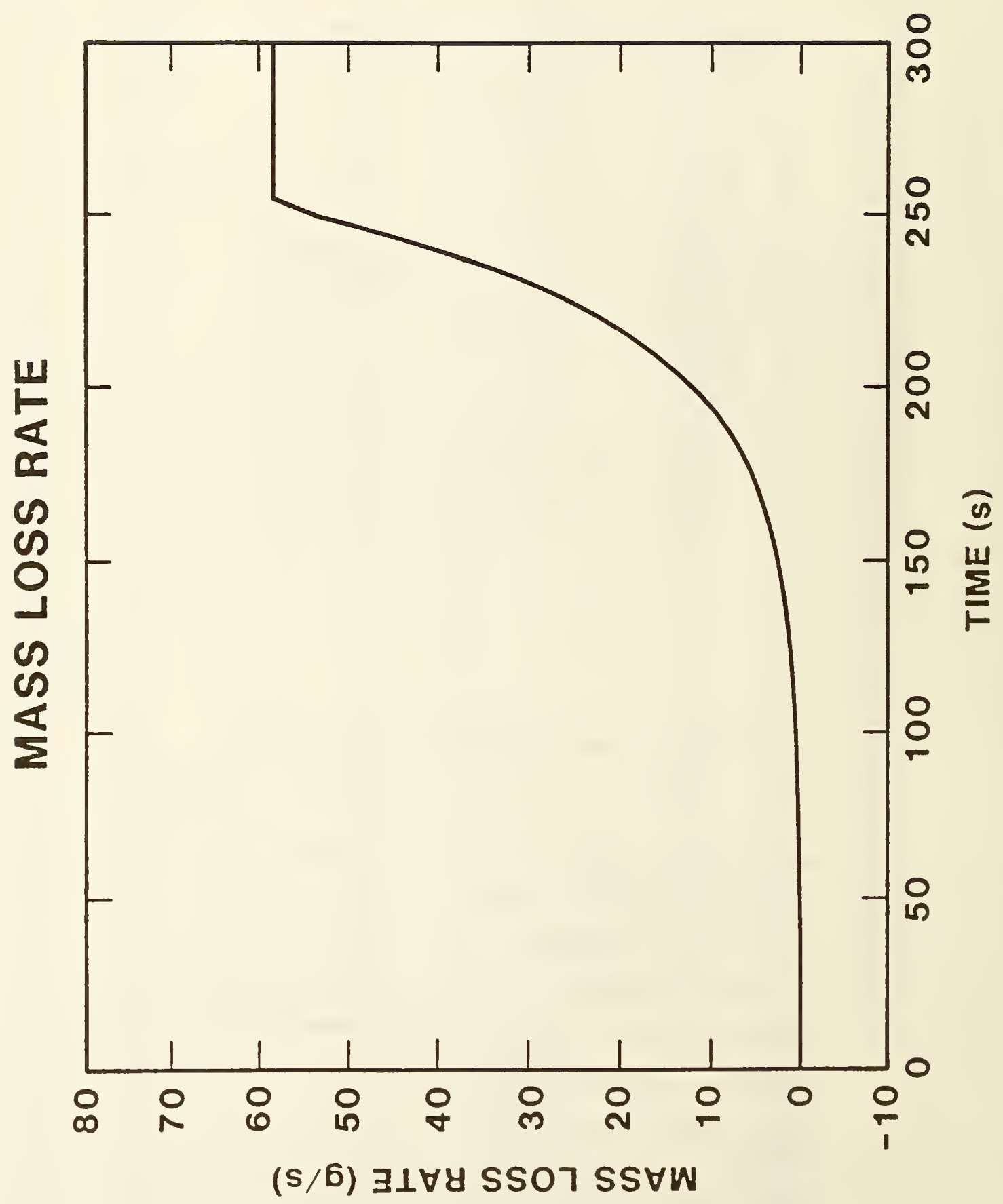

Figure E2. Mass Loss Rate for Fire Growth Example. 


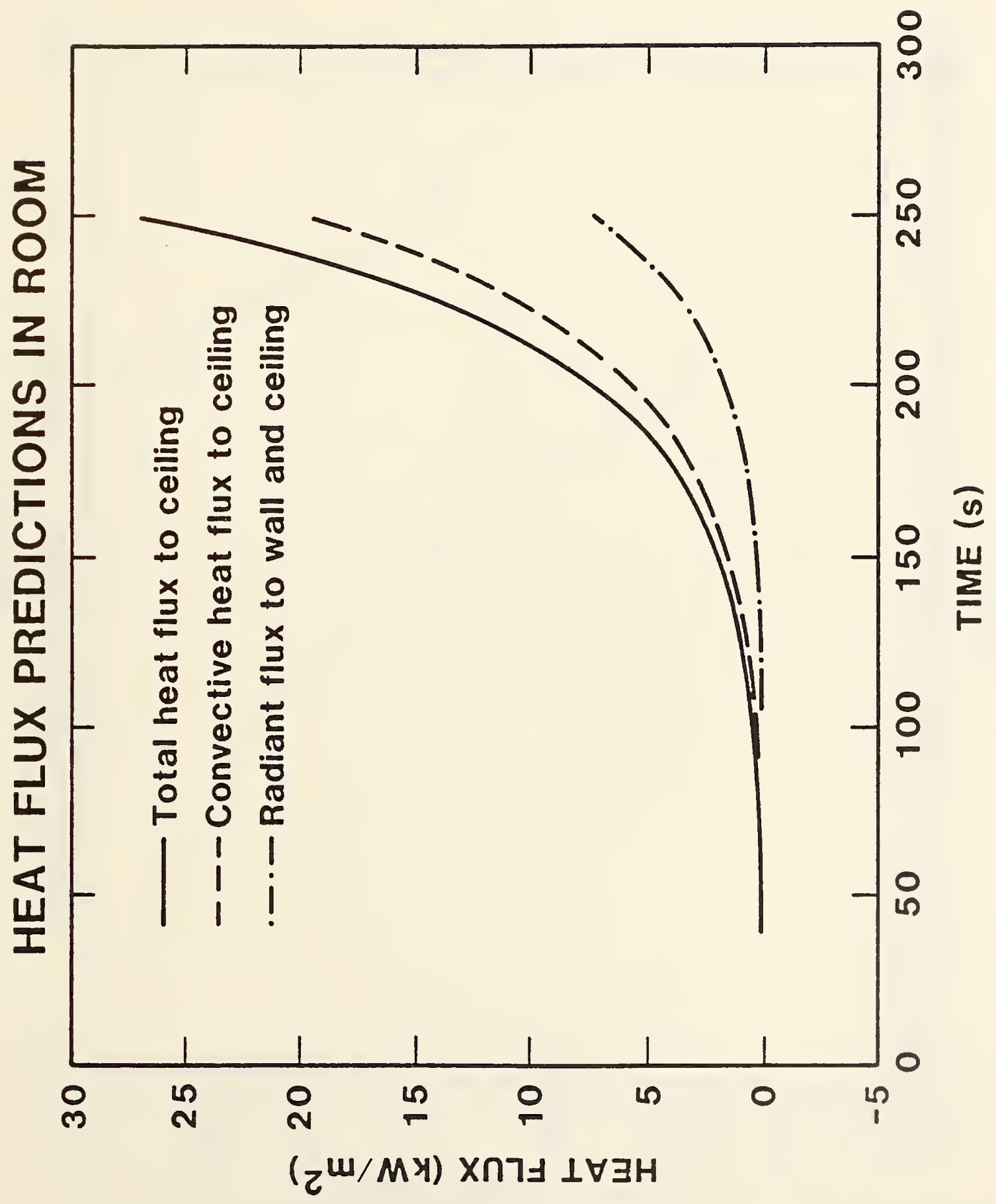

Figure E3. Heat Flux Predictions in Room for Fire Growth Example. 


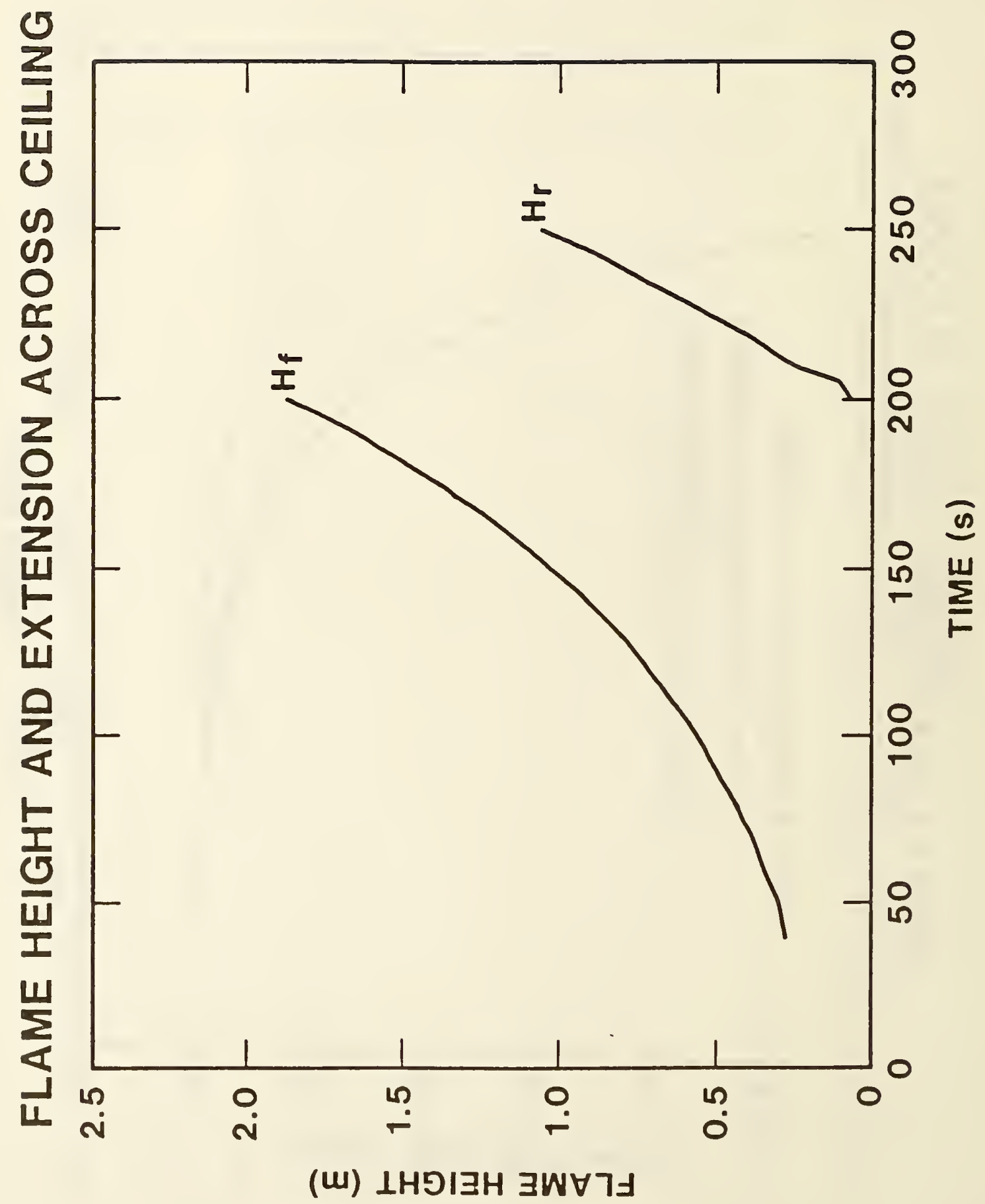

Figure E4. Flame Height and Extension Across Ceiling for Fire Growth Example. 


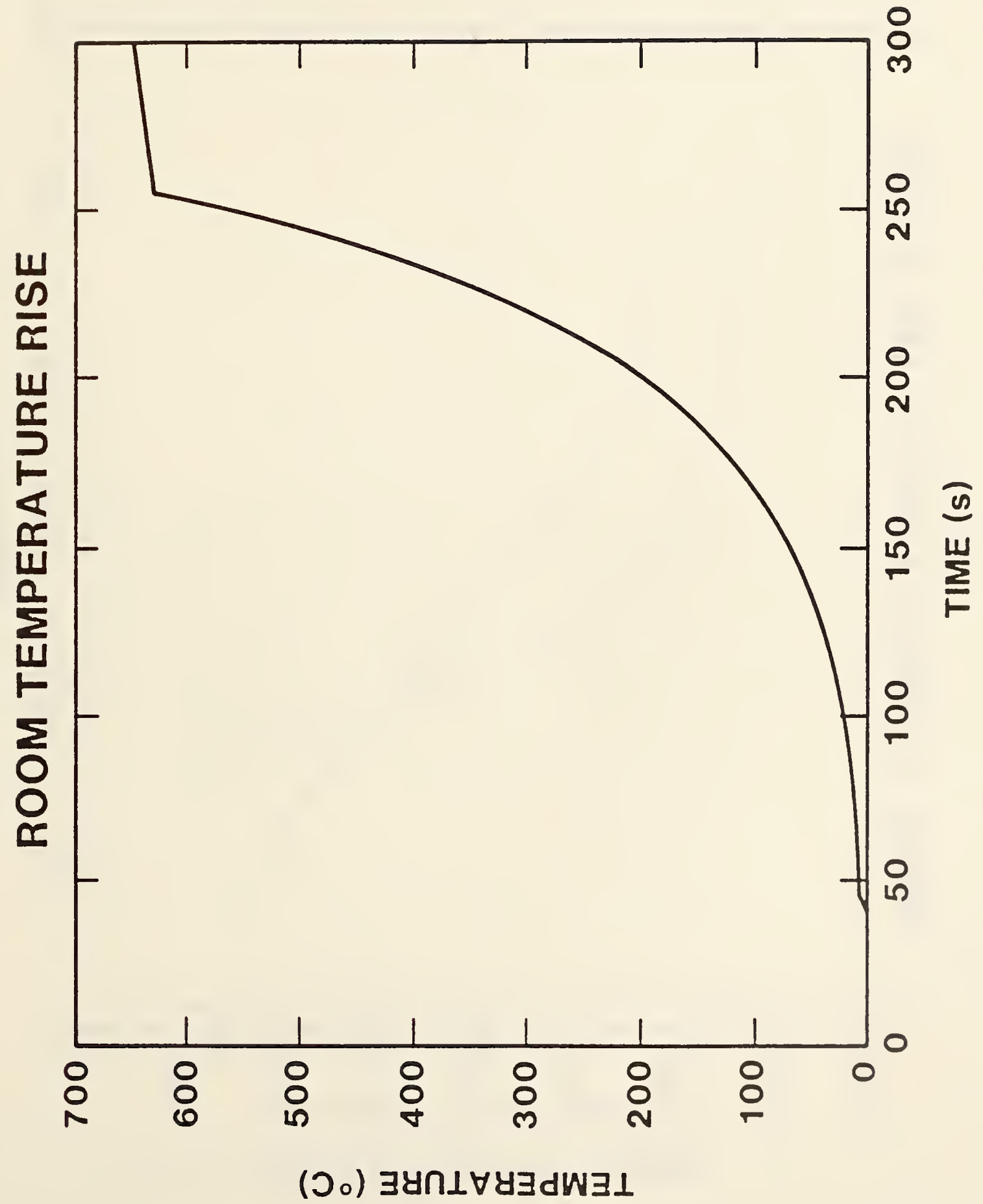

Figure E5. Room Temperature Rise for Fire Growth Example. 


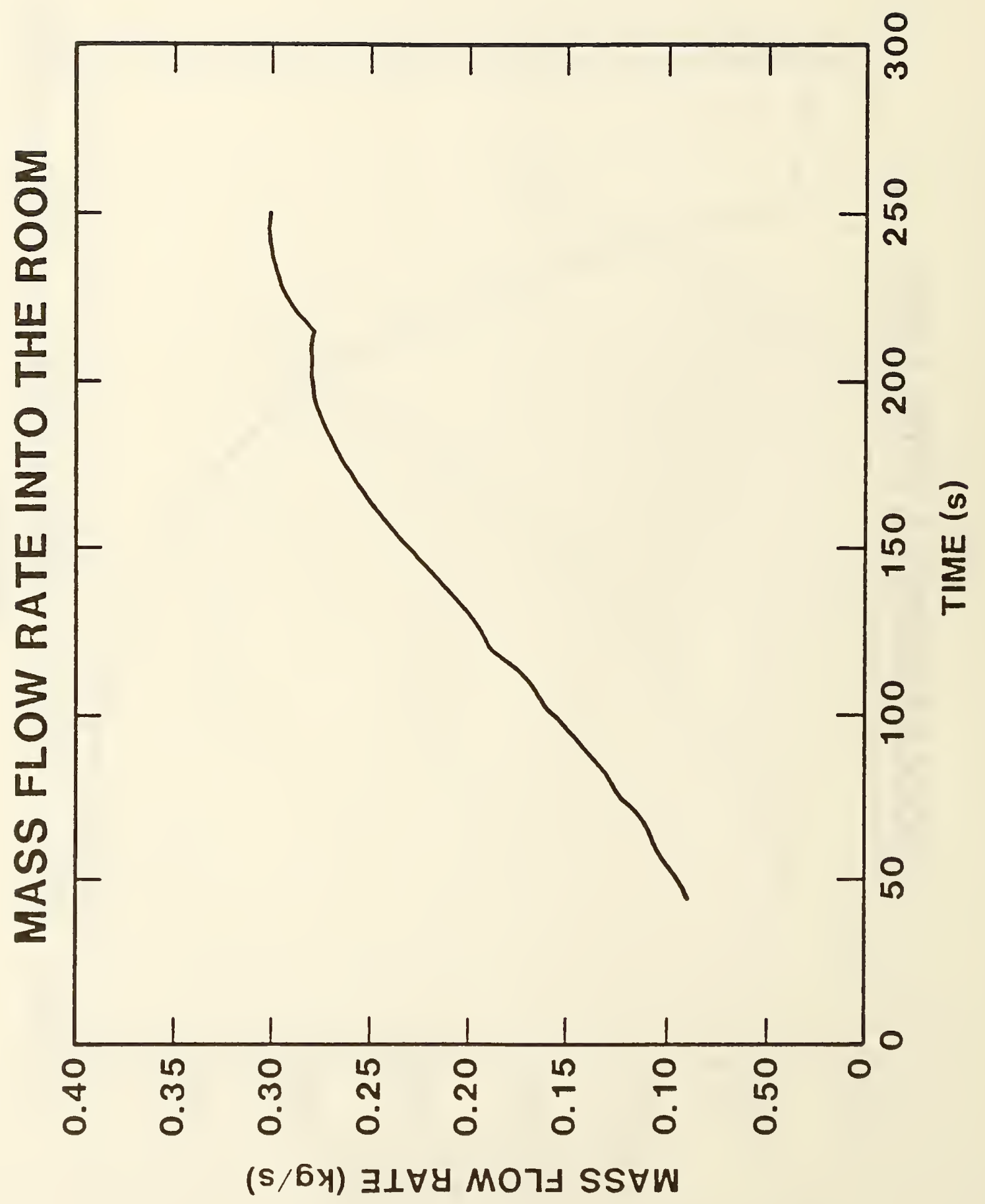

Figure E6. Mass Flow Rate into the Room for Fire Growth Example. 


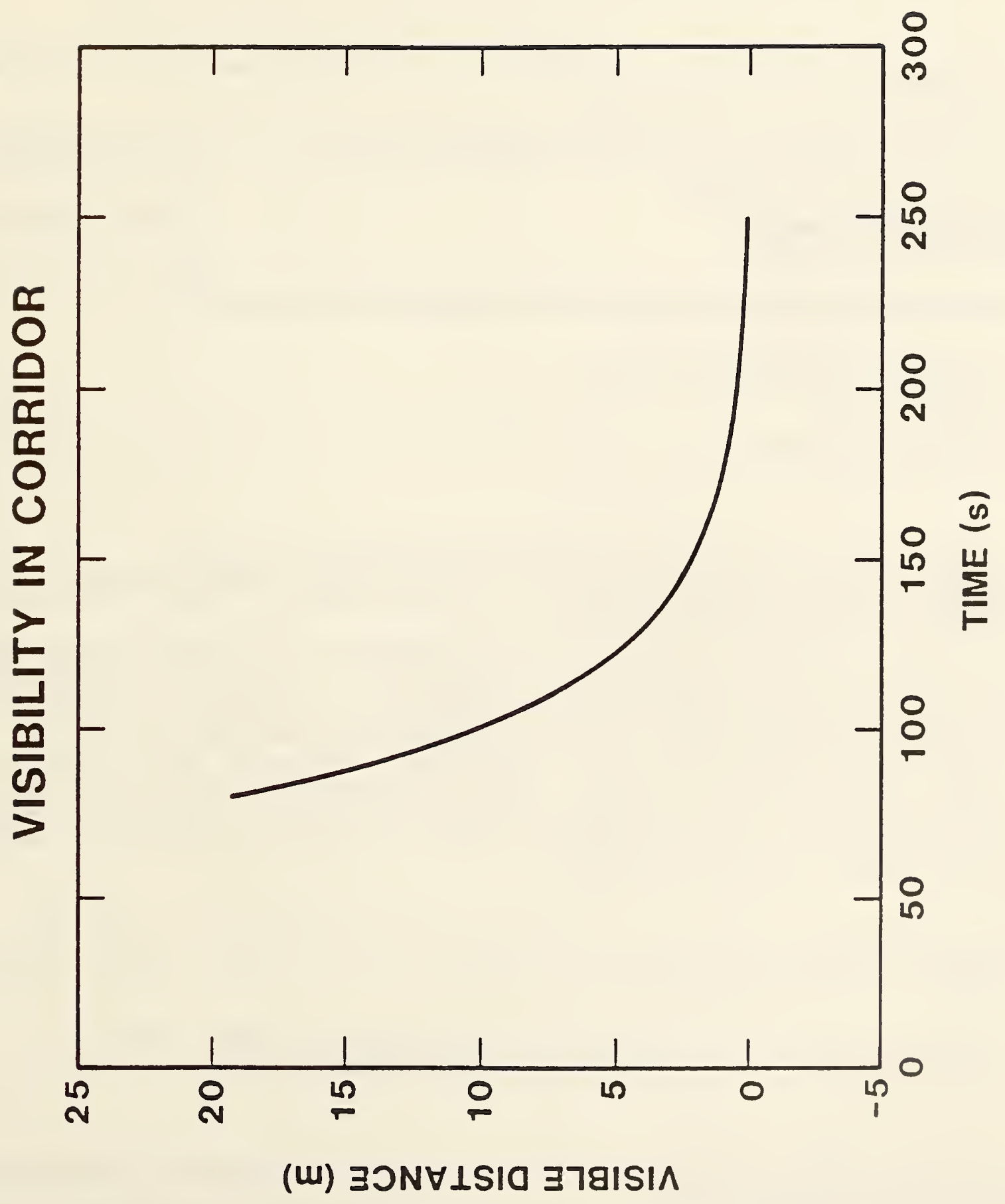

Figure E7. Visibility in Corridor for Fire Growth Example. 
NBS-114A (REV. 2-8C)

U.S. DEPT. OF COMM.

BIBLIOGRAPHIC DATA

SHEET (See instructions)

1. PUBLICATION OR

REPORT NO.

NBSIR-85/3196
2. Performing Organ. Report Nof 3. Publication Date

June 1985

4. TITLE AND SUBTITLE

Slide-Rule Estimates of Fire Growth

5. $A U T H O R(S)$

J.R. Lawson and J. G. Quintiere

6. PERFORMING ORGANIZATION (If joint or other than NBS, see in structions)

7. Contract/Grant No.

NATIONAL BUREAU OF STANDARDS

DEPARTMENT OF COMMERCE

WASHINGTON, D.C. 20234

9. SPONSORLWG ORGANIZATION NAME AND COMPLETE ADORESS (Strer, City, Stote, ZIF)

U.S. David Taylor Naval Ship

Research and Development Center

Washington, D.C.

10. SUPPLEMENTARY NOTES

Document describes a computer program; SF-185, FIPS Software Summary, is attached.

11. ABSTRACT (A 200-word or less foctual summory of most significant information. If document includes a significant bibliography or literature survey. mention it here)

A series of prediction methods have been assembled to provide an analytical basis for estimating fire growth in compartments. Solutions for each prediction method can be made using programmable scientific calculators. Prediction methods are presented for: fire size and growth rates, mass loss rates, radiant heat flux, flame height, radial flame impingement, heat flux to a ceiling, smoke filling of a room, carbon monoxide hazard with smoldering fires, temperature rise in a compartment, ventilation flow rate, flashover occurrence, corridor smoke transfer and filling, smoke concentration, visibility, flame spread rates, and fire burn time.

These predictive methods are useful for estimating many of the critical elements related to fire behavior and help provide a better understanding of this complex phenomenon.

This report appears in Appendix B in Fire Growth in Combat Ships by

J.G. Quintiere, H.R. Baum and J.R. Lawson, NBSIR 85-3159.

12. KEY WORDS (Six to twelve entries: alphobetical order; capitalize only proper names; and separate key words by semicolons) Calculators; computer programs; fire growth; fire models; room fires.

\section{AVAILABILITY}

Unlimited

$\square$ For Official Distribution. Do Not Release to NTIS

$\square$ Order From Superintendent of Documents, U.S. Government Printing Office, Washıngton, D.C. 20402.

[x] Order From National Technical Information Service (NTIS), Springfield, VA. 2216I
14. NO. OF PRINTED PAGES 56

15. Price 

